Toplum Bilimleri Dergisi - Journal of SocialSciences

ISSN: 1306-7877 e-ISSN: 2147-5644

15 Kasım / November 2019, 26 : 152-186

\title{
Popüler Kültürden Kültür Endüstrisine Bayram FM
}

Bayram FM: From Popular Culture to Culture Industry

\author{
Köksal PEKDEMİR \\ İstanbul Üniversitesi, Sosyal Bilimler Enstitüsü, Din Sosyolojisi, Doktora Öğrencisi \\ Istanbul University, Institute of Social Sciences, Sociology of Religion, Ph.D. Student \\ Istanbul, Turkey \\ koksalpekdemir@gmail.com \\ https://orcid.org/0000-0002-8979-5414
}

\section{Makale Bilgisi / Article Information}

http://dx.doi.org/10.29228/tbd.2007.39779

Makale Türü / ArticleTypes: Araştırma Makalesi / Research Article

Geliş Tarihi / Received: 7 Eylül / September 2019

Kabul Tarihi / Accepted: 2 Kasım / November 2019

Yayın Tarihi / Published: 15 Kasım / November 2019

Yayın Sezonu / PubDateSeason: Özel Sayı / Special Issue 2019

Cilt / Volume: 26

Sayfa / Pages: 152-186

Copyright (c) Published by Toplum Bilimleri Dergisi - Journal of Social Sciences. All rights reserved. www.toplumbilimleri.com 


\section{Popüler Kültürden Kültür Endüstrisine Bayram FM}

Öz: Çok farklı yansımaları olan kültür, insana giydirilen ikinci doğadır. İnsan toplumsallaşırken kültürel öğeleri benimsemekte ve hayata adaptasyon sağlamaktadır. Bu çalışmada, popüler kültürü hem oluşturma hem de yaygınlaştırma araçları arasında yer alan radyo üzerinden bir inceleme yapılmıştır. Dini yayınlar/programlar yapan bir radyo kanalı olan Bayram FM sunucuları ile dinleyicileri arasında gerçekleşen ilişki açığa çıkartılmaya çalışılmıştır. İncelemede, "sunucular, radyo dinleyicileri üzerinde rızaya dayalı hegemonik bir güce sahip mi, şayet sahipse din rızanın oluşmasında nasıl bir rol oynamaktadır" sorusunun cevabı aranmaktadır. Araştırmada özneyi daha fazla dikkate alan ve failin direnç gösterebilmesine ya da bilinçli bir şekilde tercih edebilmesine imkân tanıan "popüler kültür" kavramı yerine, kültürel öğelerin kâr amacıyla birer meta haline dönüştürülmesine ve kitlelerin söz konusu ürünler karşısında pasif konumuna gönderme yapan "kültür endüstrisi" tanımlaması tercih edilmiş ve eleştirel okul bağlamında Gramsci'nin "hegemonya" kavramsallaştırması kullanılmıştır. Bayram FM'de yayınlanan reklamlarda ve sunucu-dinleyici diyaloglarında yer alan ifadeler üzerinden hegemonyanın varlığ sorgulanmıştır. Mikro bir saha araştırması olan bu çalışma, metodolojik olarak ideografik yaklaşımı benimsemekte ve anti-pozitivist epistemolojik temele dayanmaktadır. Araştırmanın yöntemi ise içerik analizidir. Bayram FM'de yer alan altı farklı reklam ve yirmi beş sunucu-dinleyici diyaloğu incelenmiştir. Elde edilen veriler neticesinde, Bayram FM'in dinleyiciler üzerinde hegemonik bir güce sahip olduğu ve söz konusu egemenliğin rıza çerçevesinde gerçekleştiği sonucuna ulaşılmıştır. Ayrıca, Bayram FM'in, kültür endüstrisinin üreticilerinden birisi olduğu ve dini-kültürel öğeleri kâr amacıyla metaya dönüştürdüğü tespit edilmiştir.

Anahtar Kelimeler: Din Sosyolojisi, Popüler Kültür, Kültür Endüstrisi, Din, Bayram FM, Gramsci, Hegemonya.

\section{Bayram FM: From Popular Culture to Culture Industry}

Abstract: Culture with very different fragments is the second nature that is dressed to man. As people socialize, they adopt cultural elements and adapt to life. In this study, an examination is made on radio which is one of the means of creating and spreading popular culture. The relationship between the presenters and listeners of Bayram FM, which is a radio channel that makes religious broadcasts/programs, has been tried to be revealed. In the study, it is sought to answer the question "do the presenters have a hegemonic power based on consent on radio listeners, and if so, what role does religion play in the formation of this consent?" In the research, instead of the concept of "popular culture, which takes the subject 
more into consideration and allows the perpetrator to resist or to make conscious choices, the definition of "culture industry" which refers to the conversion of cultural elements to profitmaking commodities and the passive positions of the masses against these products, was preferred and Gramsci's concept of hegemony was used in the context of the critical school. The presence of hegemony is questioned through the language used in the advertisements and presenter-listener dialogues broadcasted in Bayram FM. This is a micro-field study which adopts an ideographical approach methodologically and is based on an anti-positivist epistemological ground. The method of the research is content analysis. Six different advertisements and twenty-five presenter-listener dialogues in Bayram FM were examined. As a result of the data obtained, it was concluded that Bayram FM had a hegemonic power over the audience and that the sovereignty was occurred within the framework of consent. In addition, it was ascertained that Bayram FM was to be one of the producers of the culture industry and converted religious-cultural elements into commodities for profit.

Keywords: Sociology of Religion, Popular Culture, Culture Industry, Religion, Bayram FM, Gramsci, Hegemony.

\section{Gíisiş}

Popüler kültüre yönelik yaklaşımlar bireyin davranışlarında özgür olup olmaması üzerinden şekillenmekte ve popüler kültür bu noktadan hareketle incelenmektedir. Eyleyen, popüler kültüre, özgürce tercihte bulunan aktif özne olarak mı yoksa kendisine dayatılan şeyleri kabullenen pasif bir kişi olarak mı katılmaktadır? "Bir toplumda geniş bir şekilde paylaşılan inançları ve pratikleri ve bunların örgütlendiği nesneleri dile getiren" ${ }^{1}$ popüler kültür kavramı, özneyi daha fazla dikkate almakta ve aktörün söz konusu ürünlere karşı direnç gösterebilmesine ya da bilinçli bir şekilde tercih edebilmesine imkân tanımaktadır. ${ }^{2}$

Popüler kültürün aksine, işlevsellikten çok eleştiriyi ön plana çıkartan, eyleyene karşı yapının daha fazla etki gücüne sahip olduğunu vurgulayan ${ }^{3}$ ve bu çalışmada da tercih edilen kültür endüstrisi tanımlaması ise, yapıyla aktör arasında gerçekleşen süreçte yapıyı ön plana çıkartmakta ve kültürel öğeler karşısında eyleyenleri bağımlı bireyler olarak konumlandırmaktadır. Frankfurt Okulu teorisyenlerinden Adorno ve Horkheimer gibi

\footnotetext{
${ }^{1}$ Erol Mutlu, Globalleşme Popüler Kültür ve Medya (Ankara: Ütopya, 2005), 313.

${ }^{2}$ Kültür endüstrisi ile popüler kültür kavramlarının tanımı ve farklılıkları için bk. Birsen Banu Okutan, "Diyalektik Düşüncenin Negatif Seyri Theodor W. Adorno", Doğu'dan Batı'ya Düşüncenin Seyri, ed. Bayram A. Çetinkaya (İstanbul: İnsan Yayınları, 2015), 4/789-816; Korkmaz Alemdar \& İrfan Erdoğan, Popüler Kültür ve Illetişim (Ankara: Ümit Yayıncılık, 2005).

3 Aktörün belli bir etkileme gücü olmasıyla birlikte yapının daha fazla etki gücüne sahip olduğunu düşünmekteyiz. Bu durumu "eksik özneli yapı" şeklinde kavramsallaştırmak mümkündür. Söz konusu kavram "yapımc1-yapısalcılık" terimiyle benzeşmektedir.
} 
düşünürler popüler kültürü, metalaşma, şeyleşme ve ideolojik egemenlik kavramları çerçevesinde incelemekte ve popüler kültürü tanımlamak için "kültür endüstrisi" kavramsallaştırmasını kullanmaktadır. ${ }^{4}$ Kültür endüstrisi, kültürel öğelerin kâr amacıyla birer meta haline dönüştürülmesine ve kitlelerin söz konusu ürünler karşısında pasif konumuna gönderme yapmaktadır. Bu kavramsallaştırmada failin hareket alanı sınırlıdır. Adorno özelinde değerlendirildiğinde, aktörün pasifliği daha da fazla görünürlük kazanmaktadır. ${ }^{5}$ Adorno'ya göre kültür endüstrisi, takipçilerini bilinçli olarak kendisine benzetir. ${ }^{6}$ Tüketici, sürece, -kültür endüstrisinin, müşterileri tarafından yönlendirildiğine yönelik tüm inandırma çabalarına rağmen- etkileyen/özne olarak değil, etkilenen olarak katılır. "Kültür endüstrisinin yaptığı, müşterilerinin tepkilerine uyarlanmaktan çok, onları kalpazanca imal etmektir. Kendisi de onlardan biriymiş gibi davranarak biçimlendirir müşterilerinin tavırlarını." ${ }^{7}$ Kapitalist mantıkla hareket eden kültür endüstrisi içerisinde ilerleme/yeni şeklinde sunulan her şey, sonu gelmez, standartlaşmış bir aynılığ içermekte ve endüstri kelimesi bu noktada anlam kazanmaktadır. Endüstri, üretim sürecine değil, kültürel öğenin standart hale dönüştürülmesine ve dağıtım araçlarının rasyonelleştirilmesine gönderme yapar. ${ }^{8}$

Adorno'ya göre kültür endüstrisinde tüketiciler özne olmamalarının doğal bir yansıması olarak bilinçlerini bir yana bırakır ve "uy gitsin" mantığı asıl takip edilen yönteme dönüşür. Böylece bilinçli tercihin yerine "uygitsincilik" geçmiştir. ${ }^{9}$ "Kültür endüstrisinin kategorik buyruğu artık özgürlükle hiçbir ortak yana sahip değildir. Şöyle der: Neye uyacağınız belirtilmemiş olsa dahi uyacaksınız; gücüne ve her an her yerdeliğine bir refleks olarak, herkesin, öyle ya da böyle düşündüğü şeye, öyle ya da böyle varolana uyum sağlayacaksınız." ${ }^{10}$ Kültür endüstrisi, inşa ettiği gerçekliği iyi yaşamın kendisi olarak göstermenin yanı sıra düzen ve düzenin faydalı olduğu fikrini de getirmekte, bu şekilde gelecek muhtemel eleştirilerin önüne geçmektedir. ${ }^{11} \mathrm{Ne}$ var $\mathrm{ki}$, insanların beyinlerine işlenmeye çalışılan düzen aslında statükonun devamıdır. Kültür endüstrisi, yol gösterme iddiasıyla tüketicileri kandırır ve var olan çatışmaların yerine sahtelerini koyar. Aynı zamanda, kar edenlerce belirlenen sınırların dışına çıkmamaları için insanları öğütler ve

\footnotetext{
${ }^{4}$ Max Horkheimer \& Theodor Adorno, Aydınlanmanın Diyalektiği, çev. Oğuz Özügül (İstanbul: Kabalcı Yayınevi, 1995).

5 Theodor Adorno, “Kültür Endüstrisini Yeniden Düşünürken”, çev. Bülent Doğan, Cogito 36 (2003), 76-77.

${ }^{6}$ Adorno, "Kültür Endüstrisini Yeniden Düşünürken”, çev. Bülent Doğan, 76-77.

${ }^{7}$ Theodor Adorno, Minima Moralia, çev. Orhan Koçak \& Ahmet Doğukan (İstanbul: Metis Yayınları, 2000), 207.

${ }^{8}$ Adorno, Kültür Endüstrisini Yeniden Düşünürken, çev. Bülent Doğan, 78.

${ }^{9}$ Adorno, Kültür Endüstrisini Yeniden Düşünürken, çev. Bülent Doğan, 80-81.

${ }^{10}$ Adorno, Minima Moralia, çev. Orhan Koçak \& Ahmet Doğukan, 81.

${ }^{11}$ Adorno, Kültür Endüstrisini Yeniden Düşünürken, çev. Bülent Doğan, 82-83.
} 
onları sömürür. Böylece "bilinçler zincire vurulur" ve insan hem bağımlılaşır hem de köleleşir.

Medya, kültür endüstrisinin ürünlerinin yayılmasını sağlayan mecralardan biridir. Günümüz toplumlarında kitle iletişim araçları olarak isimlendirilen radyo, televizyon, internet gibi kanallar, toplumsal üretim ve yeniden üretimin önemli bir alanı haline gelmiştir. ${ }^{12}$ Sayısal olarak fazlalığı ve birçok noktaya taşınabilir olması dolayısıyla önemli bir kitle iletişim aracı haline gelmesine ${ }^{13}$ rağmen radyo, televizyon ve internet gibi görece daha yeni iletişim araçlarının geliştirilmesiyle birlikte hem toplumsal hem de akademik dünyadaki cazibesini kaybetmektedir. ${ }^{14}$ Ancak, Türkiye özelinde Nielsen tarafından "30 ilde 12 yaş üstü bireyler üzerinde gerçekleştirilen radyo dinleyici ölçümleri 2018 Aralık ayı verilerine göre; bir günde yaklaşık 27 milyon kişi radyo dinlerken, bir hafta için dinleyici sayısı 37 milyona ulaşmaktadır. Araştırmaya göre her 10 kişiden 6'sı radyo dinlemektedir."15 Nielsen tarafından elde edilen veriler, radyonun hala bir şekilde toplumsal hayatta varlığını sürdürdügünü göstermektedir. Bununla birlikte, radyoya yönelik yapılan çalışmalara bakıldığında "akademik dünyada cazibesini kaybettiğini" kabul etmek gerekir. ${ }^{16}$ Diğer kitle iletişim araçlarıyla kıyaslandığında radyonun hak ettiği akademik ilgiyi gördügünü söylemek zordur. Dini yayınlar yapan radyolar için bu durum daha da zorlaşmaktadır. ${ }^{17}$

Türkiye'de dini grup ve cemaatlerin kitlelere ulaşmasında iletişim araçları önemli bir role sahiptir. 1990'larda yayıncılıkta sayıları artan özel televizyon ve radyo kanallarına “İslami kanallar" ${ }^{18}$ da dahil olmuştur. ${ }^{19} \mathrm{Bu}$ çalışmada, dini yayınlar yapan bir radyo istasyonu olan Bayram FM, Gramsci'nin “hegemonya” kavramsallaştırması doğrultusunda eleştirel açıdan incelenmiş ve araştırma iki nokta üzerinden gerçekleştirilmiştir: İlk olarak,

\footnotetext{
${ }^{12}$ Levent Yaylagül, Kitle İletişim Kuramları, Egemen ve Eleştirel Yaklaşımlar (Ankara: Dipnot Yayınları, 2006), $11-17$.

13 Hüseyin Altunbaş, Başlangıçtan Günümüze Radyo ve Radyo Reklamcılı̆̆l, Türkiye Yerel Radyo İstasyonlarının Reklam Aracı Olarak Kullanılışı, Sorunları ve Model Önerisi (Eskişehir: Anadolu Üniversitesi, Sosyal Bilimler Enstitüsü, Doktora Tezi, 2003), 1.

${ }^{14}$ Sinem Akyön, Türkiye'de Dini Yayıncılı̆̆ın Gelişimi: Dini Radyolar (Ankara: Ankara Üniversitesi, Sosyal Bilimler Enstitüsü, Yüksek Lisans Tezi, 2016), 12.

${ }^{15}$ Araştırmaya göre bir gün içerisinde kadınların \%52,9'u erkeklerin ise \%62'6'sı radyo dinlemektedir. Günlük ortalama radyo dinleme süresi ise 3 saat 10 dakikadır. Araştırmanın detayları için bk. Nielsen Türkiye (Nielsen), "Radyo, Etkinliğini Artırıyor; Haftada 37 Milyon Kişi Radyo Dinliyor” (Erişim 5 Nisan 2019).

${ }^{16}$ Radyoya yönelik 2000 ve öncesinde yapılan doktora çalışmalarının sayısı (21) 2000 sonrasında yapılan çalışmalardan (13) daha fazladır. Bu durum akademik ilginin azaldığ 1 iddialarını doğrulamaktadır.

17 Akyön, Türkiye'de Dini Yayıncılı̆̆ın Gelişimi: Dini Radyolar, 12.

18 “İslami kanallar” Azak’ın kullandığı bir ifade olmasından dolayı burada olduğu gibi aktarılmıştır. (Bk. Umut Azak, “İslami Radyolar ve Türbanlı Spikerler", Íslam'ın Yeni Kamusal Yüzleri, ed. Nilüfer Göle (İstanbul: Metis Yayınları, 2013), 93). İslami kanallar tanımlaması gelecek bölümlerde kullanılmayacak bunun yerine "dini yayınlar yapan radyo kanallarına" gönderme yapan "dini radyo" kavramsallaştırması tercih edilecektir. Literatürde "İslami” yerine "dini” kelimesi daha çok kullanılmasından dolayı böyle bir tercihte bulunulmuştur. "Dini grup ve cemaatler", "dini yapılar", "dini kurumlar" literatürde yer alan kullanımlardan bazılarıdır.

${ }^{19}$ Azak, "Islami Radyolar ve Türbanl Spikerler.", 93.
} 
reklamlarda kullanılan dilin çözümlemesi yapılmış, sonrasında ise radyo sunucuları ile yayına bağlanan dinleyiciler arasında geçen konuşmalar hegemonya çerçevesinde analiz edilmiştir. Dışarıdan reklam almayan Bayram FM'in kendi ürünlerini ${ }^{20}$ pazarlaması ve reklam dilini kendisinin kurması, yayın akışının çoğunluğunu sunucular ile dinleyiciler arasında geçen diyalogların oluşturması bu yönde bir incelemeyi mümkün hale getirmiştir. Çalışmada, "içerik analizi" yöntemi kullanılmıştır. "İçerik analizi, metin içeriği toplama ve analiz etme tekniğidir. İçerik iletilebilen sözcükler, anlamlar, resimler, semboller, düşünceler, temalar veya herhangi bir iletiye gönderme yapar. Metin, bir iletişim ortamı görevi gören her türden yazılı, görsel ya da sözlü öğedir."21 Araştırmada dışarıdan gözlem de söz konusudur. Bu durum, araştırılan topluluğu kendi doğal yaşam alanlarında inceleme imkânı sunmuştur.

Bayram FM, gözlem amacıyla iki buçuk ay takip edilmiş, farklı günlerde ve günün değişik zaman dilimlerinde rastlanan, altı ürünün reklamıyla, ${ }^{22}$ yirmi beş dinleyici konuşması, 25 Mart ile 26 Nisan tarihleri arasında kayıt altına alınarak deşifre edilmiştir. ${ }^{23}$ Kayıtlar tesadüfi olarak, daha fazla güne yayılması amacıyla ortalama ${ }^{24}$ yirmi dakika ile sınırlı tutulmuş ve alınan kayıtlarda herhangi bir eleme yapılmamıştır. Yirmi beş dinleyicinin on altısı kadın, dokuzu ise erkektir. Kadın-erkek konusunda kasıtlı bir ayrım yapılmaksızın tesadüfi olarak bu sayıya ulaşılmıştır. Dinleyiciler D1, D2, D3, ... ve D25 olarak, sunucular ise S1, S2, S3 ve S4 şeklinde kodlanmışlardır. Sunucuların hafta içi her gün yayın yapmaları ve uzun saatler yayında kalmalarından dolayı, aynı sunucuya, farklı gün ve saatlerde tekrar denk gelinmiştir. Takipçilerin demografik bilgileri ekler bölümünde sunulmuş, gerçek isimleri kullanılmamıştır.

Dinleyicilerin demografik özelliklerinin çıkartılması ya da dinleme alışkanlıklarının ortaya konulması gibi bir amaç güdülmediği için doğrudan katılımcılar ile görüşülmemiş, anket ya da mülakatlar yapılmamıştır. Bununla birlikte, sunucularla dinleyiciler arasında geçen konuşmalar, takipçilerin genel demografik özelliklerine yönelik ip uçları vermiştir. Radyo dinleme süresince (iki buçuk ay) hem radyoyu arayanlara hem de radyonun sosyal

\footnotetext{
${ }^{20} \mathrm{Bu}$ ürünler değişiklik göstermektedir. Kitap, Kur'an, Yasin cüzleri, hurma, çörek otu, krem gibi çok farklı alanlarda ürünler satılmaktadır. Bunlar aşağıda açıklanacaktır.

${ }^{21}$ Lawrence Neuman, Toplumsal Araştırma Yöntemleri, çev. Sedef Özge (Ankara: Yayınodası, 2014), 1/466.

${ }^{22}$ Reklam başlığı altında bu ürünler hakkında bilgi verilecektir.

${ }^{23}$ Kayıt tarihleri eklerde yer alan kişi bilgilerinin yanında verilmiştir.

${ }^{24}$ Ortalama ifadesini kullanılmasının iki nedeni vardır. Birincisi kayıtlar dinleyici ile sunucu arasında geçen bir konuşma esnasında başlamış, bu ilk konuşmacının kayıtları çözümlemeye dahil edilmemiştir. Böyle bir yolun tercih edilmesinin nedeni hem sonraki dinleyicinin kim olduğunun bilinmemesini sağlamak hem de dinleyici kitlesini doğru bir şekilde ortaya koymak ve tarafsızlığı sağlamaktır. Bu durum kayıtları bazen kısaltırken bazen de uzatmıştır. İkinci neden ise kayıt esnasında aralara reklam ve ilahiler girdiği için bazı kayıtlarda dinleyici-sunucu konuşması on beş dakikanın altında kalırken bazı kayıtlarda ise kayıtlar yirmi dakikalara kadar sarkmıştır.
} 
medya hesaplarında yer alan profillere bakıldığında, dinleyicilerin demografik özelliklerinin Akgül'ün ${ }^{25}$ araştırmasında ortaya çıan sonuçlarla benzeştiğini söylemek mümkündür. ${ }^{26}$

\section{LITTERATÜR DEĞERLENDIRMESI}

Kitle iletişim araçlarıyla bağlantılı birçok araştırma yapılmış olmasına rağmen, meseleyi dini boyutuyla inceleyen çalışmaların sayısı oldukça azdır. Bu durum din ve radyo söz konusu olduğunda daha da fazla geçerlilik kazanmaktadır. Sosyal bilimler alanında radyo başlığı altında 34'ü doktora olmak üzere toplamda 189 tez yazılmıştır. Bu araştırmalar arasında, sürece dini dahil eden bir doktora çalışması, 2 tane de yüksek lisans tezi vardır. Din sosyolojisi alanında ise radyoya yönelik yapılan herhangi bir teze ulaşılamamıştır. $\mathrm{Bu}$ başlık altında öncelikle yüksek öğretimde kurumlarında yapılan tezler ele alınacak, sonrasında hem Türkiye'de yapılan hem de Türkçeye tercüme edilen kitaplara yer verilecek, en sonunda ise dini radyolara yönelik kaleme alınmış araştırmalara değinilecektir.

Din ve radyo alanında değerlendirilebilecek tek doktora çalışması Bölükbaş tarafından gerçekleştirilmiştir. ${ }^{27}$ Bölükbaş incelemesinde "topluluk radyosu uygulama örneği olarak Alevi inanç grubuna hitap eden Cem Radyo ve Sünni cemaatlerden biri olan İskenderpaşa cemaatine ait olan Akra FM" 28 kanallarını incelemiştir. Araştırmada, toplulukların kendi kültürlerini sürdürmesinde topluluk radyolarının önemli bir etki gücü olduğu, grupların genel olarak kendilerine yakın olan radyoları takip ettiği sonucuna ulaşılmıştır. ${ }^{29}$ Din ve radyo başlı̆̆ı kapsamında gerçekleştirilmiş diğer çalışma ise Akyön

\footnotetext{
${ }^{25}$ Mehmet Akgül, "Medya ve Din: Radyo İletişimi ve Gözyaş1 FM Örneği”, Türk-İslam Medeniyeti Akademik Araştırmalar Dergisi 6/1 (Temmuz 2008), 48-52.

${ }^{26}$ Akgül çalışmasında dinleyicilerin çoğunluğunu orta yaş ve üzeri bireylerin oluşturduğu, kadınların fazla olduğu, genel olarak eğitim seviyelerinin ve sosyo-ekonomik durumlarının düşük olduğu sonucuna ulaşmıştır. Burada da benzer sonuçlar elde edilmiştir. Hem radyoyu aradıklarında kim oldukları, nereden aradıkları ve ne iş yaptıkları hakkında bilgi veren dinleyiciler hem de radyo adına açılmış sosyal medya hesaplarında yer alan takipçilerin bilgilerinden hareketle dinleyici profili üzerinde şu çıkarsamaları yapmak mümkündür: Yaş dağılımına bakıldığında her yaş grubundan insan tarafindan dinlenmekle birlikte çoğunlukla orta yaş ve üzeri bireyler tarafından dinlenmekte, cinsiyet dağılımında ise kadınlar tarafından daha fazla dinlendiği anlaşılmaktadır. Öğrenim düzeyine bakıldığındaysa eğitim seviyesinin düşük olduğu görülmektedir (konuşma ifadeleri, çalıșılan ișler ve beğeniler bu konuya dair bilgi vermektedir). Meslek dağılımında ise ev kadınlarının, herhangi bir meslekte çalışmayanların (yaşlı kadınlar) ve düşük gelirli meslek gruplarında çalışanların (tekstil fabrikası, çiftçi, akaryakıt saha satış sorumlusu vb.) çoğunlukta olduğu anlaşılmaktadır. Meslekle bağlantılı olarak akıllara gelir düzeylerinin de düşük olduğu gelmekle birlikte bu konuda çok fazla bir gözlem yapılamamıştır. Kontörü olmadığı için arkadaşından arayan dinleyiciler (D16) bu yorumu desteklemekle birlikte bu konu hakkında gözlemler oldukça sınırlı kalmış̧ır. Medeni duruma yönelik olarak evlilerin daha fazla olduğunu söylemek mümkündür (çocukları ve eşi için dua isteyen, kaç çocuğu olduğunu ve eşinin mesleğini söyleyen dinleyicilerden hareketle böyle bir çıkarsama yapılmıştır). İkame edilen yerler çoğunlukla şehirlerdir. İş amacıyla göçülen şehir faktörü de burada ön plana çıkmaktadır. Bk. Akgül, "Medya ve Din: Radyo İletișimi ve Gözyaşı FM Örneği”, 48-52.

${ }^{27}$ Kenan Bölükbaş, Türkiye'de İnanç Gruplarının Kültürel Varoluşunda Topluluk Radyolarının Rolü (İstanbul: Marmara Üniversitesi, Sosyal Bilimler Enstitüsü, Doktora Tezi, 2016).

${ }^{28}$ Bölükbaş, Türkiye'de İnanç Gruplarının Kültürel Varoluşunda Topluluk Radyolarının Rolü, 4.

${ }^{29}$ Bölükbaşı'nın çalışmasında ortaya çıkan sonuca benzer bir durum herhangi bir cemaatle doğrudan bağlantısı bulunmayan Bayram FM için de geçerlidir. Bu ise Bayram FM etrafında "hayali cemaat" şeklinde bir
} 
tarafından yapılmış yüksek lisans tezidir. ${ }^{30}$ Akyön'ün araştırmasında “Türkiye'de yayın yapan dini radyolar incelenerek sayıları, sahiplik yapıları, radyo ve yayıncılı̆̆a bakış açıları ile radyonun işleyişi üzerinde durulmuş, böylelikle Türkiye'de dini radyo yayıncılığının profili ortaya konulmaya çalışıl(mıştır)." 31 Akyön dini radyo alanında 83 radyo kanalı tespit etmiş, bunlar arasında evreni temsil kapasitesini esas alarak Ankara, İstanbul ve Konya illerinde yayın yapan dini radyolar ile görüşmeler yapmaya çalışmıştır. ${ }^{32}$ Bölükbaş'ın aksine Akyön, "bu radyolara karakterini veren din, yapısı gereği dogmatiktir" şeklinde bir açıklamayla dini radyoların alternatif ya da topluluk radyoları kapsamında değerlendirilmesinin yanlış olacağını söylemektedir. ${ }^{33}$ Din ve radyo alanında yapılmış sonuncu tez ise Yetgindağ ${ }^{34}$ tarafından kaleme alınmış yüksek lisans tezidir. Yetgindağ araştırmasında Akra FM örneğinden hareketle, dini yayınların dinleyici tarafından nasıl alımlandığını ve radyonun, dinleyicilerinin hangi ihtiyaçlarını karşıladığını ortaya koymaya çalışmıştır. Yetgindağ, Akra FM'in bilişsel, duygusal, kişisel, sosyal ve rahatlama ihtiyaçlarını karşıladı̆̆ı sonucuna ulaşmıştır. ${ }^{35}$

Din ve radyo başlığı altında gerçekleştirilen tezlerin yanı sıra, 2000 yılından sonra yapılmış, radyonun yurtdışında ve Türkiye'deki tarihini dikkate alan ve radyo dinleyicileri üzerinde duran üç doktora çalışmasına da yer verilecektir. Tezinde radyonun tarihini sunan Altunbaş, aynı zamanda radyo istasyonlarının işleyişi, radyo program formatları, radyo yayın saatleri, dönemleri ve radyo dinleyicileri gibi pek çok konuda bilgi vermektedir. ${ }^{36}$ Altunbaş'ın araştırması radyoya dair genel bilgi içermesinden dolayı önemlidir. Güney ise incelemesinde "radyo programcılarının dinleyicilerini nasıl tanımladıkları, dinleyicilerle ilişkilerini nasıl tasarımladıkları ve deneyimledikleri ve bu ilişkinin biçimlenmesinde rol oynayan faktörleri" araştırmıştır. ${ }^{37}$ Örneklem olarak Power Türk, Radyo D, TRT İstanbul Radyosu, Cem Radyo, Açı Radyo ve Radyo Net olmak üzere altı farklı istasyonu seçmiş, yayın yöneticileri/sorumluları ve programcılardan oluşan otuz sekiz kişi ile derinlemesine

kavramsallaştırmaya kapı aralamaktadır. Kavram için bk. Benedict Anderson, Hayali Cemaatler, çev. İskender Savaşır (İstanbul: Metis Yayınları, 2017).

${ }^{30}$ Akyön, Türkiye'de Dini Yayıncılı̆̆ın Gelişimi: Dini Radyolar.

${ }^{31}$ Akyön, Türkiye'de Dini Yayıncılı̆̆ı̆n Gelişimi: Dini Radyolar, 1.

${ }^{32}$ Akyön, çalışmasının ilk aşamasında Bayram FM'i de araştırmasına dahil etmiş ancak Bayram FM yetkilileri tarafından yoğunluk gerekçesiyle görüşme talebi reddedilmiş, bunun üzerine Bayram FM'i çalışmadan çıkartmıştır.

${ }^{33}$ Akyön, Türkiye’de Dini Yayıncılı̆̆ın Gelişimi: Dini Radyolar, 136.

${ }^{34}$ Büşra Yetgindağ, Dini Radyo Yayınlarının Alımlanması: Akra FM Örneği (İstanbul: Arel Üniversitesi, Sosyal Bilimler Enstitüsü, 2015).

${ }^{35}$ Yetgindağ, Dini Radyo Yayınlarının Alımlanmast: Akra FM Örneği, 113.

${ }^{36}$ Altunbaş, Başlangıçtan Günümüze Radyo ve Radyo Reklamcılığı, Türkiye Yerel Radyo Istasyonlarının Reklam Aracı Olarak Kullanılışı, Sorunlarl ve Model Önerisi.

${ }^{37}$ Hamdi S. Güney, Radyo Yayıncılığının Dijitalleşmesi ve Radyo Dinleyicisinin Dönüşümü (İstanbul: Marmara Üniversitesi, Sosyal Bilimler Enstitüsü, 2007), 149. 
mülakatlar gerçekleştirmiş, aynı zamanda programları da incelemiştir. ${ }^{38}$ Güney'in tezi radyo istasyonları üzerinde saha araştırması yapması ve radyo programcılarının, alıcıları nasıl konumlandırdıklarını ortaya koymasından dolayı dikkate değerdir. Öztürk ise radyo incelemelerinin dijitalleşmesini, bu süreçte radyo dinleyicisinin dönüşümünü ele almıştır. Öztürk'ün çalışması alandaki boşluğu dolduran bir araştırma olması açısından önem taşımaktadır. ${ }^{39}$ Brecht'in Radyo Kuramı ve Sinema Üzerine başlığını taşıyan kitabı radyoya yönelik ulaşılan tek tercüme eserdir. Brecht çalışmasının küçük bir bölümünü radyo kuramına ayırmış, "radyo modası geçmiş bir buluş $\mathrm{mu}^{\prime}$ sorusunu sormuş ve radyo yöneticilerine birtakım önerilerde bulunmuştur. ${ }^{40}$

Türkiye'de radyo ile ilgili kaleme alınmış sadece iki telif kitaba ulaşılmıştır. İlki Aziz'in Radyo Yayıncılı̆̆ı başlığını taşıyan çalışmasıdır. ${ }^{41}$ Kitabına radyo yayınının tarihçesiyle başlayan Aziz, radyo yayın sistemleri ve örgüt yapısı, radyo yayınının teknik özellikleri ve işlevleri, program türleri, program yapım, radyo çalışanları; tanım ve görevleri, radyo dinleyici araştırmaları ve Türkiye'de radyo yayıncılığı gibi pek çok alanda okuyuculara bilgiler sunmaktadır. Diğeri ise Kuruoğlu'nun Propaganda ve Özgürlük Aracı Olarak Radyo başlığını taşıyan çalışmasıdır.42 Kuruoğlu bu eserinde propaganda amaçlı bir güç olarak radyoyu ele almakta, propaganda aracı olarak uluslararası dini yayın yapan radyolara da yer vermektedir. Bununla birlikte, din ve radyoyu konu alan müstakil kitaplara ise ulaşılamamıştır. Bu konuda Okutan'ın Türkiye'de Popüler Kültür Din ve Kadın başlığını taşıyan çalışmasında, dindar kadınların radyodaki temsilleri, radyo dinleme zamanları ve dinledikleri radyolar sunulmuştur. ${ }^{43}$ Okutan'ın araştırmasında ortaya çıkan sonuçlara göre genel olarak radyo, televizyon ve internete göre daha az kullanılmakta ve özellikle akşamları, ev işleri yaparken ve araba kullanırken dinlenmektedir. ${ }^{44}$ Okutan radyoya yönelik ortaya çıkan sonuçları "başörtülü katılımcıların radyo ile kurdukları ilişkisellik yoğun olmamakla birlikte, eğlence, dinlenme ve öğrenme amaçlı olduğu görülmektedir" şeklinde özetlemektedir. ${ }^{45}$

Din ve radyo alanı makaleler açısından da son derece fakirdir. Bu konuda toplamda iki araştırmaya ulaşılmıştır. Akgül'ün “Medya ve Din Radyo İletişimi ve Gözyaşı FM

\footnotetext{
${ }^{38}$ Güney, Radyo Yayıncılığının Dijitalleşmesi ve Radyo Dinleyicisinin Dönüşümü, 8-9.

${ }^{39}$ Bahar Öztürk, Radyo Yayıncılı̆̆ının Dijitalleşmesi ve Radyo Dinleyicisinin Dönüşümü (İstanbul: Marmara Üniversitesi, Sosyal Bilimler Enstitüsü, 2017).

${ }^{40}$ Bertolt Brecht, Radyo Kuramı ve Sinema Üzerine, çev. Süheyla Kaya (İstanbul: Agora Kitaplı̆̆ 1,2012 ).

${ }^{41}$ Aysel Aziz, Radyo Yayıncılı̆̆ (İstanbul: Nobel Yayınları, 5. Basım, 2018).

${ }^{42}$ Huriye Kuruoğlu, Propaganda ve Özgürlük Aracı Olarak Radyo (İstanbul: Nobel Yayınları, 2006).

${ }^{43}$ Birsen Banu Okutan, Türkiye'de Popüler Kültür Din ve Kadın (İstanbul: Düşün Yayınları, 2013).

${ }^{44}$ Okutan, Türkiye'de Popüler Kültür Din ve Kadın, 227.

${ }^{45}$ Okutan, Türkiye'de Popüler Kültür Din ve Kadın, 230.
} 
Örneği" başlığını taşıyan makalesi bunlardan birisidir. 46 "Bu çalışmanın amacı, birbiriyle organik bağları olmayan modern kentli bireyleri, dini radyo formatıyla oluşturduğu dinleyici kitlesini, bir çeşit dini grup şeklinde biçimlendiren Gözyaşı FM'in ‘dini bir dünya görüşü geliştirmede' ve grupsal bir davranış oluşturmadaki etkisini ölçmeye çalışmak(tır)." ${ }^{47}$ Diğer araştırma ise Azak'ın "İslami Radyolar ve Türbanlı Spikerler" makalesidir. Azak bu incelemesinde İstanbul merkezli yayın yapan dini radyolarda spiker olarak görev yapan bir grup kadınla söyleşiler yapmış ve çalışmasının sonucunda genel olarak dini radyo istasyonlarında kadınların etkin olmadıkları sonucuna ulaşmıştır. ${ }^{48}$

\section{KURAMSAL ÇERÇEVE}

Çalışmada, Bayram FM, eleştirel kuram temelinde Gramsci'nin 'hegemonya' kavramı çerçevesinde sorunsallaştırılmaktadır. Hegemonya kavramsallaştırmasının sahibi olan Gramsci'nin içerisinde bulunduğu gerçeklik, savaş sonrasında kapitalizmin ekonomik krizden çıkmayı başardığı ve kendisini stabilize ettiği, Batı'da sosyalist devrimlerin ya mağlup olduğu ya da hayatiyet kazanamadığı bir gerçekliktir. ${ }^{49}$ Marx'ın söylediklerinin tersi yönde gelişen bu koşullar kapitalist toplumların politik ve ideolojik kaynaklarının yeniden analizini gerekli hale getirmiştir. Gramsci'nin çabası böyle bir ihtiyacın ürünüdür. Gramsci'nin içerisinde bulunduğu Marksist gelenek, kapitalist gelişmenin boyutları ve ekonomik krizler ile siyasal değişimlerin bağlantısı hakkında analizlerde bulunma konusunda güçlü olmakla birlikte, siyasal iktidar biçimlerinin, toplumsal sınıflar ve siyasal temsil ile kültürel ve ideolojik boyutlar arasındaki somut ilişkilerin analizinde zayıf kalmıştır. Bu bağlamsal arka planda Gramsci'nin yapmak istediği, tarihsel materyalizm yaklaşımının mekanist yönlerini (ekonomi bunların en güçlüsüdür) kuramsal olarak eleştiriye tabi tutma ve Marksist gelenek içerisinde siyasetin işgal ettiği alanı daha da genişletme isteğidir. Gramsci bu amaçla Feuerbach Üzerine Tezler'e ve Marx ile Engels'in tarihiyle ilgili metinlere yönelmiştir. Bunların yanı sıra Marksist olmayan İtalyan idealist filozof Croce'nin, etik-politik alanla, yani toplumun bir aradalığını sağlayan ideolojik, ahlaki ve kültürel çimentoya yönelik düşüncelerinden de faydalanmıştır. Aynı zamanda Gramsci, Marx'ın Ekonomi Politiğin Eleştirisine Katkı'da altyapı ile üstyapı hakkında yazdıklarını antiekonomist bir yaklaşımla yeniden ele almıştır. Ona göre bu eserde, değişen sosyo-ekonomik durumların, kendi başlarına siyasal değişimi üretmeyip sadece söz konusu değişimleri ortaya çıkartacak koşulları oluşturacağı söylenmektedir. Bu değişimlerin ortaya çıkmasında

\footnotetext{
${ }^{46}$ Akgül, "Medya ve Din Radyo İletişimi ve Gözyaşı FM Örneği ”,

${ }^{47}$ Akgül, "Medya ve Din Radyo İletişimi ve Gözyaşı FM Örneği ”, 45.

${ }^{48}$ Azak, "Islami Radyolar ve Türbanl Spikerler".

${ }^{49}$ Davis Forgacs (haz.), Gramsci Kitabı, çev. İbrahim Yıldız (Ankara: Dipnot Yayınları, 2018), $229-230$.
} 
önemli olan şey siyasal alanda elde edilen güç ilişkileridir ve hegemonya bu noktada anlamlı hale gelmektedir. ${ }^{50}$

Gramsci'ye göre tarihsel politik incelemelerde düşülen yanılgılardan biri organik olanla konjonktürel olan arasında kurulan ilişkidir. ${ }^{51} \mathrm{Bu}$ durum gerçekte dolaylı etki gücüne sahip sebeplerin, doğrudan etkileyen nedenler olarak algilanmasina ya da tam tersi ilişkiselliklere yol açar. Birincisinde bir 'ekonomizm', ikincisinde ise 'ideolojizm' aşırılığ vardır. İlk durumda mekanik nedenlerin fazlasıyla ön plana çıkartılması diğerinde ise iradeci ve bireysel faktörlerin abartılması söz konusudur. Bu durum altyapı ya da üstyapının öncelemesiyle kalmaz, diğerinin yanlış konumlandırmasına da yol açar. Gramsci'nin yazıları, Marksist bir gelenekten beslenmesinin doğal sonucu olarak, Marksist teoriyi, yapıcı bir eleştiriyle daha da güçlendirme gibi bir amaca matuftur. Bu doğrultuda Gramsci tarihsel politik araştırmalarda ilk yanlış olarak kabul ettiği ekonomizmle mücadeleye girişmiştir. Ona göre "ekonomist hipotez, dolayımsız bir güç öğesinin -yani, doğrudan ya da dolaylı bir finansal desteğin- var olduğunu ileri sürer ve bununla yetinir. Fakat bu yeterli değildir." ${ }^{52} \mathrm{Bu}$ durumda, daha geniş bir analiz, ancak hegemonya ile etik-politik ilişkiler alanında gerçekleşebilir. ${ }^{53}$

Gramsci hegemonyanın, “...salt ekonomik ve siyasal olgu ve etkinlikler açısından değil, kendi devlet anlayışı ve kültürel olguya, kültürel etkinliğe, kültürel bir cepheye onay verilmesi açısından başat bir öneme sahip olduğunu" söylemektedir. ${ }^{54}$ İdeolojiler keyfilikten uzaktır ve siyasal mücadeleye yönelik nedenler dolayısıyla, savaşılması ve tahakküm araçları olarak, yönetilenleri (hegemonyaya maruz kalan) yönetenlerden (hegemonya uygulayan) düşünsel açıdan bağımsızlaştırmak için gerçek doğalarının açığa çıkartılması gereken tarihsel olgulardır. ${ }^{55}$ Ona göre praksis felsefesi, tarihte gerçekleşen çelişkileri barışçıl çözüme kavuşturmak gibi bir amacı gütmemesi yönünden diğer felsefelerden ayrılmaktadır. Gramsci için çelişki:

“Egemen grupların madun sınıflar üzerinde hegemonya kurmak ve onların rızasını kazanmak için başvurdukları bir yönetim enstrümanıdır; yönetim sanatında kendilerini eğitmek isteyen ve bütün hakikatleri, nahoş olanları bile, bilmeye ve

\footnotetext{
${ }^{50}$ Forgacs, Gramsci Kitabı, çev. İbrahim Yıldız, 229-230.

${ }^{51}$ Forgacs, Gramsci Kitabı, çev. İbrahim Yıldız, 245.

${ }^{52}$ Forgacs, Gramsci Kitabı, çev. İbrahim Yıldız, 265-266.

${ }^{53}$ Forgasc, Gramsci Kitabı, çev. İbrahim Yıldız, 266.

${ }^{54}$ Forgacs, Gramsci Kitabı, çev. İbrahim Yıldız, 236.

${ }^{55}$ Forgacs, Gramsci Kitabı, çev. İbrahim Yıldız, 238.
} 
yönetici sınıfın aldatmalarından ve hatta kendi kendilerini bile aldatmaktan sakınmaya eğilimli madun sınıfların dışavurumudur." 56

Güç ilişkileri içerisinde filizlenmiş ideolojiler 'parti' haline gelir ve bu noktada birbirleriyle mücadeleye ve çatışmaya girer. Bu süreç, içlerinden birinin üstün gelip, hükmünü uygulayana, toplumsal alanın her noktasında kendisini kabul ettirene dek sürer. $\mathrm{Bu}$ sadece ekonomik ve siyasal erklerin birliğini değil aynı zamanda düşünsel ve moral bir birliktelik de doğurur. Galip gelen ideoloji, mücadeleye neden olan sorunları korporatif olarak değil, evrenselleştirerek ele alır ve böylece temel bir toplumsal grubun bağımlı grup üzerinde hegemonya kurmasına yol açar. Hâkim taraf, bağımlı tarafların genel çıkarlarıyla somut biçimde koordineli olur ve bu rızayı doğurur. ${ }^{57}$ Hegemonya kavramı tek yönlü bir ilişki ağını çağrıştırmakla birlikte "hegemonyanın yeniden üretimi" amacıyla hegemonya, karşılıklı bir ilişki aracılığıyla kurulmaktadır. Hegemonyada etki değil etkileşim söz konusudur. Aksi oldukça indirgemeci bir yaklaşım olacaktır ve insanları "kendine pazarlanan kimliklerin pasif tüketicileri" 58 olarak görecektir. Hegemonyaya maruz kalış zorlamadan çok rıza çerçevesinde şekillenmektedir.

Gramsci'ye göre hegemonya olgusu, hegemonyaya maruz kalacak grupların çıkarlarını ve eğilimlerini dikkate almak ve belli bir uzlaşının oluşturulması, bir başka ifadeyle, yönetici grubun ekonomik-korporatif açıdan fedakarlıklarda bulunması gerektiğini ön kabul olarak benimser. ${ }^{59}$ Böylece tahakküm eden sınıf rızayı elde eder. Rızanın oluşmasında bazı etkenler söz konusudur. Egemen sınıfın toplumsal hayata dayattı̆̆ı genel talimata geniş halk gruplarının rıza göstermesinin nedenlerinden biri; egemen sınıfın üretim dünyasındaki konumundan ve işlevinden dolayı sahip olduğu itibar ve onun doğurduğu güvendir. İkincisi ise, devlet aygıtının yasal olarak disipline eden "zor uygulaması" dır. Bu aygıt, hegemonya krizinde ortaya çıkan durumu kontrol altına alıp yön vermesi amacıyla oluşturulmuştur. Rızanın sağlanamaması ya da sürdürülememesi sonucunda yönetenler ile yönetilenler arasında bir çatışmanın çıkması muhtemeldir. Bu, tahakküm eden sınıfın hegemonya krizidir. Bu kriz egemen sınıfın savaş gibi önemli bir siyasal eylemde geniş kitlelerin rızasını almada başarısız olması ya da hegemonyaya maruz kalan grubun direnç göstermesinden dolayı ortaya çıar. ${ }^{60}$

\footnotetext{
${ }^{56}$ Forgacs, Gramsci Kitabı, çev. İbrahim Yıldız, 239.

${ }^{57}$ Forgacs, Gramsci Kitabı, çev. İbrahim Yıldız, 250.

${ }^{58}$ Stephen P. Turner, "Giriş: Sosyal Teori ve Sosyoloji”, çev. Nazan Gece, Sosyal Teori ve Sosyoloji, Stephen P. Turner (İstanbul: Küre Yayınları, 2013), 8.

${ }^{59}$ Forgacs, Gramsci Kitabı, çev. İbrahim Yıldız, 257.

${ }^{60}$ Forgacs, Gramsci Kitabı, çev. İbrahim Yıldız, 281.
} 
Hegemonya, iktidar bağlamında anlamlı hale gelmektedir. İktidar ilişkisi ve bunun bir sonucu olarak hegemonya toplumsal hayatın hemen her noktasında ortaya çıar. İktidar sadece büyük İ ile sağlanmamakta küçük i'li iktidarlarda da gerçekleşmektedir. Aileden okula, dini kurumlardan iş yerlerine kadar birçok noktada ilişkiler, iktidar bağlamında şekillenmektedir. Ailede baba ile çocuk ya da karı ile koca, okulda öğretmen ile öğrenci ya da müdür ile öğretmen, dini kurumda imam ile cemaat ve işyerinde patron ile çalışan arasında gerçekleşen iletişimler iktidar temelinde olmaktadır. Çalışmanın konusunu oluşturan Bayram FM'i -devletin kendisine sağladığı iktidar alanı içerisinde yayın hakkına sahip olup, yeri geldiğinde devlet tarafından RTÜK aracılığıyla denetime tabi tutulsa dadaha çok, küçük i'li iktidar çerçevesinde değerlendirmek gerekir.

Bayram FM radyosunda, Gramsci'nin hegemonya kavramsallaştırmasıyla tanımladığı sürece benzer bir durum, yani hegemonya söz konusudur. Bayram FM sunucuları ile dinleyicileri arasında düşünsel ve moral açıdan bir birlikteliğin varlığı, hegemonyanın ve hegemonyaya karşı rızanın oluşmasının zeminini sağlamaktadır. Ortak düşünsel ve ahlaki temel ise din özellikle de folk dini anlayıştır. Hegemonyanın kurulmasında dinin önemli bir araç olarak kullanılmasının yanı sıra Bayram FM sunucuları, dinleyicilere, olması gerekenin tam da kendilerince sunulan şey olduğunu hissettirerek hegemonyayı evrenselleştirmekte ve böylece rızanın oluşmasını sağlamaktadır. Aynı şekilde dinleyicilerin içerisinde bulundukları sosyo-ekonomik durumda hegemonyaya karşı rızayı beslemektedir. Çalışmanın uygulama bölümünde hegemonya ve rıza kapsamında bu konular araştırılacaktır.

Radyo dinleyicilerini sınıflandıran birtakım çalışmalar vardır. Bunlardan biri Hedges'in radyo dinleyicilerini; 'istasyon hayranları', 'radyo hayranları', 'müzik hayranları' ve 'haber hayranları' olmak üzere dört kategoriye ayırdığı sınıflandırmadır. ${ }^{61}$ İstasyon hayranları favori olan radyo istasyonlarını dinlerken, radyo hayranları ise açıç̧a belli bir istasyonu tercih etmemektedir. Üçüncü grupta yer alanlar müzik severler, dördüncü gruptakiler ise haber ve bilgi edinmek amaciyla radyoyu dinleyenlerdir. Birinci gruptaki dinleyicilerin çoğunluğunu \%46'yla 25-44 yaş aralığındaki kadınlar, ikincisindekileri \%34 ile 35 yaş altı kadınlar, üçüncüsündekileri \%11'ile 25-45 yaş aralığında erkekler, dördüncüsündekileri ise \%8 ile 35 yaş üstü insanlar oluşturmaktadır. ${ }^{2}$ Bu doğrultuda, Bayram FM dinleyicilerini, belli bir istasyona bağlı kalan ve uzun yıllar aynı istasyonu takip

\footnotetext{
${ }^{61}$ William Well vd., Advertising Principles \& Practive (New Jersey: Prentice Hall, 2000), 273-274. Akt. Altunbaş, Başlangıçtan Günümüze Radyo ve Radyo Reklamcılı̆̆ı, Türkiye Yerel Radyo İstasyonlarının Reklam Aracı Olarak Kullanılıșl, Sorunları ve Model Önerisi, 88.

${ }^{62}$ William Well vd., Advertising Principles \& Practive, 273-274. Akt. Altunbaş, Başlangıçtan Günümüze Radyo ve Radyo Reklamcılı̆̆ , Türkiye Yerel Radyo İstasyonlarının Reklam Aracı Olarak Kullanılışı, Sorunları ve Model Önerisi, 88.
} 
eden dinleyiciler olmalarından dolayı, istasyon hayranları kategorisinde değerlendirmek gerekir. Radyoyu arayan takipçilerin "uzun yıllardır Bayram FM dinleyicisiyim", "gece yatana kadar dinliyorum" ve "hafta sonu bile dinliyorum" gibi ifadeleri, istasyon sever dinleyiciler olduklarını desteklemektedir. Radyo takipçilerine yönelik bir diğer sınıflandırma ise dinleyicilerin radyo programlarına katılımlarına göre yapılmakta, dinleyiciler "aktif dinleyiciler ve pasif dinleyiciler olarak gruplandırılmaktadır. Aktif dinleyiciler radyo istasyonlarında programlara, yarışmalara telefonla katılırlar ve dinlemek istedikleri müzik parçalarını DJ'lere söylerler. Pasif dinleyiciler ise programa ve yarışmalara katılmazlar."63 Bayram FM her iki türde de takipçiye sahiptir. Ancak burada aktif dinleyiciler üzerinden bir inceleme yapılmıştır.

\section{DINI BİR RADYO ${ }^{64}$ KANALI: BAYRAM FM}

Radyoların, televizyon kanallarına kıyasla daha ucuz olması, onları cazip hale getirmektedir. Dini radyolar, haberleşmeyi kolaylaştırmak, cemaat aidiyetini arttırmak gibi rollerinin yanında bir propaganda aracı olarak da işlev görmektedir. Öyle ki radyo kanalları, ulaştıkları noktalara, içerisine dahil oldukları dini grubun İslam anlayışlarını da yaymışlardır. ${ }^{65}$ Bayram FM tarihçesi hakkında herhangi bir resmi bilgiye ulaşılamamıştır. Resmi internet sayfasında kanala dair açıklama yer almamaktadır. Bayram FM üzerinde yapılmış bir çalışmaya da ulaşılamamıştır. Radyonun Facebook, ${ }^{66}$ Instagram $^{67}$ ve Twitter ${ }^{68}$ gibi sosyal medya platformlarında hesapları bulunmaktadır. En aktif kullanılan sosyal medya adresi Facebook'tur ${ }^{69}$ ve Facebook hesapları Bayram FM ismindedir.

Bayram FM radyosunda hâkim olan din anlayışına bakıldığında, halk dini ya da folk din olarak isimlendirilen dini anlayışın egemen olduğu görülür. Folk din, formel dinin karşısında yer alır. Formel din; metne bağlı olup, sistemleşmiş bir yapıya sahipken, folk ise metinden çok halkın dinden anladıkları öğelere dayanır. “Dini metinleri okumada ve dini anlamada yetkin olan otorite, formel dinin taşıyıcısıdır. Onların yorumlamaları çeşitli

\footnotetext{
${ }^{63}$ William Well vd., Advertising Principles \& Practive, 273-274. Akt. Altunbaş, Başlangıçtan Günümüze Radyo ve Radyo Reklamcılı̆̆ , Türkiye Yerel Radyo İstasyonlarının Reklam Aracı Olarak Kullanılışı, Sorunları ve Model Önerisi, 88.

64 "Dini radyo" kavramsallaştırması için on sekizinci dipnota bakınız.

${ }^{65}$ Azak, "İslami Radyolar ve Türbanlı Spikerler", 96.

${ }^{66}$ Bayram FM ismiyle beş ayrı Facebook hesabı ve bir de Bayram FM dinleyenler grubu olmak üzere altı farklı hesap bulunmaktadır. İlk sırada yer alan Bayram FM hesabını 129968 kişi, ikincisini ise 2739 kişi beğenmiştir. Üçüncü sırada yer alan Bayram FM dinleyenler Grubunu 12610, dördüncü sırada bulunan Bayram FM hesabını 274 (grup), beşinci Bayram FM sayfasını 786, altıncı Bayram FM sayfasını ise 26 kişi beğenmiştir.

672581 kişi takip etmektedir.

${ }^{68} 612$ kişi tarafından takip edilmektedir.

${ }^{69} \mathrm{Bu}$ durum genellikle belli bir yaşın üzerindeki takipçi profiline sahip olan Bayram FM dinleyicileri ile uygunluk göstermektedir. Çünkü Facebook kullanımında yaş ortalaması yükselmektedir. Facebook kullanımında yaş faktörüne dair bk. Köksal Pekdemir, Din ve Zihniyet: Gençlik Üzerine Bir Araştırma (İstanbul: İstanbul Üniversitesi, Sosyal Bilimler Enstitüsü, Yüksek Lisans Tezi, 2018), 117-118.
} 
şekillerde halka ulaşır; halk da kendi zihin dünyası veya habitus sınırına göre dini ve sembolleri hayatında işlevsel hale getirir."70 Bayram FM'in folk dini anlayışa sahip olduğunu gösteren birtakım nedenler bulunmaktadır. Kur'an ve Yasin cüzlerinin dağıtılmasının ${ }^{71}$ bol sevap kazandıran davranış olarak sunulması ve kabul edilmesi, kandillerin kutsal zamanlar olduğuna yapılan yoğun vurgu, gül ve tespih gibi bazı nesnelerin kutsallaştırılması bunlardan bazılarıdır.

Bayram FM'in dini bir radyo kanalı olarak kabul edilmesinin sebepleri arasında, ilk sırada, programların içeriği yer almaktadır. Radyoda bulunan programlar dini motifler taşımakta ve bu durum sunucular tarafından da açık bir şekilde ifade edilmektedir. Ayrıca, sunucular, takipçileri namaz ve orucun önemi gibi dini konularda bilgilendirmekte, dinleyiciler, sunuculara hocam diye hitap etmektedir. Radyoda ilahiler dışında herhangi bir müzik türüne yer verilmemektedir. ${ }^{72}$ Radyonun resmi internet sitesinde, dini, İslami, Kuran, sohbet, ilahi, zikirli ilahi, müziksiz ilahi, ezgi şeklinde sekmeler bulunmaktadır. Radyoyu arayan dinleyiciler konuşmalarına genellikle "selamun aleyküm" diyerek başlamakta, programcılar ise arayanlardan çoğunlukla salavat getirmelerini istemektedir. Radyoda, Kur'an, Yasin cüzleri, hurma, mevlit hediyeleri gibi dini motifli ürünlerin satışı da yapılmaktadır. Hem sunucular hem de dinleyiciler tarafından dini jargon (inşallah, maşallah, Allah, Peygamber, Allah razı olsun, Peygamberimizin şefaatine nail olun vb.) sıkça kullanılmakta ve dualar konuşmaların önemli bir bölümünü oluşturmaktadır. Radyoda ara ara Kur'an okunmakta ve perşembe günleri dini konularda soru cevap programı yapılmaktadır. ${ }^{73}$ Radyonun resmi sosyal medya hesaplarındaki paylaşımlarda, bazı sunucuların İslam dinine uygun olduğu düşünülen sarık, cübbe gibi kıyafetler giydiği görülmektedir. Ayrıca, radyoya ait sosyal medya hesaplarında paylaşımı yapılan video ve görseller dini içeriklidir. Bütün bu veriler Bayram FM'in dini bir radyo kanalı olarak kabul edilmesinde rol oynamıştır.

Bayram FM hakkında RTÜK toplamda üç cezai işlemde bulunmuştur. Bunlarda biri 2014, diğer ikisi ise 2017 yılında gerçekleşmiştir. 2014 yılında verilen ceza, RTÜK'ün kendi sayfasında bulunmamaktadır. Ceza, Akşam gazetesinde haber olarak yer almaktadır. ${ }^{74}$ Ceza,

\footnotetext{
${ }^{70}$ Okutan, Türkiye'de Popüler Kültür Din ve Kadın, 36-38.

${ }^{71}$ Formel dini anlayışta, dağıtılmasının sevap kazandırabileceğinin kabulüyle birlikte bireyin kendisinin okuması ve hayatına aktarmasına yapılan vurgu daha yoğundur.

72 İlahiler genel olarak arabesk tarzdadır ve bu, dinleyici profiliyle uygunluk göstermektedir.

${ }^{73}$ Gelen sorulardan bazıları şu şekildedir: 1- Erkek: Hocam Coca Cola tersten okununca aloc acoc Arapçada Allah yok Muhammed yok demekmiş bildiğim kadarıyla, bu sebepten dolayı içmek caiz olur mu? 2- Kadın: Herkesin olduğu gibi bizim de kazaya kalan namazlarımız var, bu namazlarımızı normal vakitlerdeki sünnetlerin yerine kaza kılsak olur mu? 3- Kadın: Üç aylar tespihi diye bir tespih söyledi arkadaşımız, üç aylara özel tespihat var mı? 4- Kadın: Kardeşler arasında küs olarak vefat eden kişi cennetin kokusunu bile alamaz deniliyor doğru mu? 5- Erkek: Kardeşimin süt kardeşiyle evlenebilir miyim?

${ }^{74}$ Akşam Gazetesi, “Din Sömürüsüne RTÜK Cezası” (Erişim 14 Nisan 2019).
} 
17.04.2014 tarihinde Kur'an-1 Kerim reklaminda, sunucunun “Kur'an'ları burada boynu bükük bırakmayın, ikişer, üçer alın" ifadelerinden ve aynı sunucunun kanser hastası olan bir kişiye dua ederek iyileştirdiğini söylemesinden dolayı, dini duyguların istismarı ve haksız çıar sağlama gerekçeleriyle verilmiş ve radyo, reklam gelirinin yüzde biri oranında para cezasına çarptırılmıştır. 11.07.2017 tarihinde, saatlik 12 dakika olan reklam süresini 27 dakikayla aştığı gerekçesiyle işlem yapılmışร5 ve 1.486 Türk lirası para cezasıyla, söz konusu durumunu, tekrarlanması halinde yapılacaklar konusunda uyarı verilmiştir. ${ }^{76}$ 06.09.2017 tarihinde;

“...sunucu tarafından doğrudan dinleyicilere hitap ederek, dinleyicilerin de radyoda satılan ürünlerden almak suretiyle kuruluşa destek vermelerinin istendiği, dinleyicilerin satılan ürünleri aldıkları takdirde sevap kazanacaklarının, aksi takdirde radyonun yayınına devam edemeyerek kapanacağının belirtilerek, ürünün satışının yapılmaya çalışıldığı, dolayısıyla mezkur yayının dinleyiciyi yanıltıcı ve tüketicinin çıkarlarına zarar verici bir nitelik taşıdığı" gerekçesiyle 1.486 Türk lirası para cezası ${ }^{77}$ uygulanmıştır. ${ }^{78}$

Bayram FM dinleyicilerinin sayısını ortaya çıkartmak zor olsa da programlara gelen telefonlar ve katılma şansını yakalayan dinleyicilerin uzun uğraşlar sonunda bağlanabildiklerini söylemeleri, ${ }^{79}$ sosyal medya hesaplarını beğenenlerin sayıs1 ${ }^{80}$ ve Bayram FM konserleri adıyla farklı şehirlerde gerçekleştirilen konserlere katılımlardaki yoğunluklar¹ dinleyici sayısının fazlalığına dair ip uçları vermektedir.

\subsection{Bayram FM'de Reklamlar}

Radyo yayını süresince dışarıdan herhangi bir reklam alınmamaktadır. Tüm reklamlar radyo tarafından satılan ürünler hakkındadır. Reklamlar genellikle canlı yayın şeklinde gerçekleşmekte, bu ise aynı ürün reklamında farklı ifadelerin kullanılmasına imkân sağlamaktadır. Reklamı yapılan nesnelerin ve daha fazlasının yer aldığı Bayramdan.com

\footnotetext{
${ }^{75}$ Cezanın verildiği tarih: 09 Ağustos 2017.

${ }^{76}$ Radyo Televizyon Üst Kurulu, (RTÜK), “Üst Kurul Kararları” (Erişim 14 Nisan 2019).

${ }^{77}$ Cezanın verildiği tarih: 02 Ekim.2017.

${ }^{78}$ Radyo Televizyon Üst Kurulu, (RTÜK), “Üst Kurul Kararları” (Erişim 14 Nisan 2019).

${ }^{79}$ Bağlananların genelde aynı kişiler olması ve sürekli dinleyiciler ve istikrarlı arayıcılar olması bu durumu bir nebze zedelemekle birlikte dinleyicilerin geneli yoğunluk dolayısıyla bağlanamamaktan yakınmaktadır. Bazen de program sunucuları tarafından son günlerde arayanların yeni arayanlara müsaade etmesi ve aramamaları talep edilmektedir.

${ }^{80}$ Örneğin hesaplardan birisi yüz otuz bin kişi tarafından beğenilmiştir.

${ }^{81}$ Youtube, "Bayram FM Konseri”" (Erişim 24 Mayıs 2019).
} 
adresinden de satışlar yapılmaktadır. Sitede yer alan ürünler; mevlit hediyelikleri, Kur'an-ı Kerim, gıda ürünleri, seccadeler, Yasin cüzleri, dini kitaplar, mutfak eşyaları olmak üzere yedi başlık altında kategorilendirilmiştir. Bu çalışmada, Medine Sugai hurması, Kur'an, Yasin cüzü, Kur'an-1 Kerim hatim seti, krem ve çörek otu yağı olmak üzere toplam altı farklı reklamın ses kaydı alınmış ve bunlar daha sonra yazıya geçirilmiştir. ${ }^{82}$ Reklamı yapılan ürünlerde herhangi bir elemeye gidilmemiş, rastlanan tüm reklamlar kayıt altına alınmıştır. Gelecek bölümde, reklamlarda kullanılan ifadelere yer verilecek, analizler ise değerlendirme ve sonuç kısmında yapılacaktır.

\subsubsection{Zamanın Kutsallığının Kullanılması}

Reklamlarda, Müslümanlarca kutsal kabul edilen birtakım gün ve gecelerin ürün satışında kullanılması sık karşılaşılan bir durumdur. Aşağıdaki ifadeler bu durumu ortaya koymaktadir:

Bugün (Cuma) yapılan iyilikler, güzellikler bol sevap kazandırıyor. Belki bugün size ulaşamayabilir ama bugün niyetiyle yaptık ya siparişlerimizi, bugün niyetiyle Allah'ı Teala hazretleri size de bol bol sevap verecektir. ... Bugün biraz daha cömert olmanızı istiyorum. Allah cömert olan kullarını sever. İki adet, en azından iki adet sipariş verebiliriz. ${ }^{83}$ (Kur'an reklamı, 29.03.2019).

Yoluna kurbanım diyenler, Allah rızası için şu mübarek Miraç Kandili'nin hürmeti ve bereketiyle arayalım. Hepimiz arıyoruz. Ben bile arıyorum. Evet evet kardeşlerim haydin arayın. Hepinizin ismini görmek istiyorum. Haydi canlar 39 liraya. 39 liralık bir kadir kıymet yok mu? ... Vallahi büyük fazilettir. Özellikle bu Miraç gecesi. ... Evet kardeşlerim arayın. ... Allah rızası için bu gece kandil, katılın kardeşlerim, rabbim sizi görüyor. ... Kim bu geceye hürmet ederse vallahi karşılığını görür. (Yasin cüzü reklamı, 02.04.2019).

Kardeşlerim şu mübarek üç aylarda, Ramazan'da ve Ramazan dışındaki zamanlarda bu güzel Medine hurmalarına yer verin. ... Sadece 245 liraya on kilo Medine Sugai hurması gönderiyorum. (Medine hurması reklamı, 25.03.2019).

\footnotetext{
${ }^{82}$ Reklamlardan üç tanesi dinleyici konuşma kayıtları içerisinde, kalanlar ise bağımsız olarak kaydedilmiştir.

83 Aynı reklamda üç aylar vurgusu da yer almaktadır: "Bakın Allah nasip ederse Kur'an ayı geliyor. Camilerimizde yine hatimler inecek, mukabeleler olacak. Konu komşu ne yapacaksınız, bir arada toplanıp ramazan ayı süresince hatimler indirilecek, mukabeleler okunacak."
} 


\subsubsection{Kutsal Nesnelerin Kullanılması}

Kur'an'1 Kerim ve Yasin cüzlerinin yanı sıra, doğrudan dini bir anlam taşımayan objeler de kutsallaştırılıp satış malzemesine dönüştürülmekte ve atfedilen kutsallık daha fazla satış amacıyla araçsallaştırılmaktadır. Gül de bu objelerden birisidir. Yasin cüzünün reklamını yapan S1, gülü, "kardeşlerim işte on tane Yasin alana on tane gül kokulu tespih hediye edeceğiz. Efendimizin en çok sevdiği gül ve onun kokusu peygamber kokusu. Gül kokulu on adet tespihi şerifi hediye edeceğiz" diyerek kutsal bir objeye dönüştürmekte ve bunu alıcılara karşı kullanmaktadır.

\subsubsection{Torbaları Dolduralım...}

Reklamı yapılan ürünlerin satın alınmasının bir ibadet olduğu ve bu ürünlerin alınması halinde bol bol sevapların, Allah'ın rızasının, Peygamberin şefaatinin kazanılmasına vesile olacağı vurgusu çok sık tekrarlanmaktadır. Aşağıda farklı reklamlarda yer alan ifadeler bu durumu ortaya koymaktadır:

Allahu Teala Hazretleri size de bol bol sevap verecektir. ... Bana ne getirdin diyecek kabir ne getirdin? ... Herkes bırakıp gidecek. Eş dost, çoluk çocuk. Hacı anne, hacı baba neyle baş başa kalacaksın. Amellerimizle baş başa kalacağız. O yüzden bugünden hazırlanalım inşallah. Torbalarımızı dolduralım dostlar. Torbalarımızı dolduralım. Sevap hanelerimiz dolsun dostlar. (Kur'an reklamı, 29.03.2019).

Rasulullah'ın mucizesi, Hz. Kur'an'ın kalbi Yasin-i Şerif kampanyamıza Allah rızası için katılalım bu gece. Bakın canlar bakın bakın vallahi melekler seyrediyor bizi, melekler bakıyor melekler (yüksek bir ses tonu kullanıyor). ... Alıp bu Yasinleri dağıtalım, Peygamber efendimizin şefaatine nail olalım. Aramaya devam edin. ... Siz şu Yasinleri efendimizin adına hediye niyetiyle alıyorsunuz ya bu size yeter. ... Kardeşlerim hem alın dağıtın hem bu yayınları ayakta tutun hem de şu kandilin hürmetine günahlardan arınanlardan olalım. Çağrı merkezi numaralarımızı program boyunca aramaya devam edin. (Yasin cüzü reklamı, 02.04.2019).

\subsubsection{Haydin Bu Dualara Nail Olalım...}

Reklamlarda kullanılan bir diğer yöntem ise ürünleri alanlar için yapılan dualardır. Dinleyicilere yönelik dualarla, ürünün sipariş verilmesi teşvik edilmekte, duadan faydalanmak isteyenlerin ürünleri satın alması gerektiği mesajı verilmektedir: 
Şu mübarek Miraç Kandili'nin yüzü suyu hürmetine, Allah'ım ne günahınız varsa silsin. Allah'ım ne kadar dileğiniz varsa nasip etsin bu gece. Allah evinize huzur, bereket, rızkınızı bol eylesin. Allah sizi ve çoluğunuzu çocuğunuzu kazadan beladan esirgesin kardeşlerim. Haydin bu dualara nail olalım. Arayın kardeşlerim. (Yasin cüzü reklamı, 02.04.2019).

Yarın huzuru mahşerde Rabbim Kur'anını ömürde bir defa hatmettim diyen kullardan olmak niyeti ve duasıla inşallah. İşte kardeşlerim muhteşem bir kampanya Kur'a-1 Kerim hatim seti. ... Alın kardeşlerim kargo, KDV dahil 99 lira. Bakın sınırlı sayıda var o yüzden acele edin. Yarına bırakmayın. (Kur'an-ı Kerim hatim seti, 11.04.2019).

\subsubsection{Kur'an'1 Hediye Edersek Nurun Ala Nur Olur...}

Kur'an ve Yasin cüzü gibi, bir defa alındığında uzun yıllar kullanılabilecek aynı ürünlerin satılmasından dolayı, bu ürünlerin ihtiyaç amaçlı değil daha çok başkalarına hediye, cami ve Kuran Kursları gibi merkezlere bağış amacıyla sipariş verilmesi teşvik edilmekte ve böylece satışlarda süreklilik sağlanması amaçlanmaktadır. Bu durum da sevap kazanmakla ödüllendirilmektedir:

Gönül rahatlığıyla camilerimize, Kur'an Kurslarımıza bırakabilirsiniz dostlar. ... Gelin sizlere sunduğumuz yepyeni Kur'an'1 Kerimleri gittiğiniz yere, sevdiklerinize hediye edin. ... Hele bir de hediyelerin en büyügü Kur'an'ı Kerim'i hediye edersek nurun ala nur olur. Okundukça okuyanın sevap kazandığı gibi vesile olan da sevap kazanır. Bundan asla şüphemiz yok. ... Evet belki bir cami yaptıramıyor olabiliriz, bir çeşme, bir Kur'an Kursu yaptıramıyor olabiliriz ama bir Kur'an hediye ederek bol bol sevap kazanabiliriz hayattayken. Vefat ettikten sonra da sadaka-i cariyemiz olsun. İşte numaralarımız 0212... Bana ne getirdin diyecek kabir ne getirdin? İnşallah alarak hediye ettiğiniz Kur'an'lar sizlere kabirde bir nur olur. Mahşer-i Kübra'da şefaatçiniz olsun. (Kur'an reklami, 29.03.2019).

Allah rızası için bunları dağıtalım. Ne olur bakın her zaman böyle kandiller geçmez. (Yasin cüzü reklamı, 02.04.2019). 


\subsubsection{Efendimizin Ruhuna Hediye Edelim...}

Ürünlerin satışında başvurulan bir yöntem de peygambere hediyedir. Ürünler peygambere hediye edilme niyetiyle satılmakta, alıcılar peygambere hediye sunacakları düşüncesiyle daha fazla motive olmaktadır. Böylelikle, alıcılara "Peygambere hediyede bulunmayacak misın" mesajı verilmekte ve onlar üzerinde duygusal/manevi bir baskı kurulmaktadır:

Peygamberimizin bu gecesine (Miraç Kandili) sevinenler, işte alıp dağıtacağımız bu Yasinleri efendimize hediye niyetiyle dağıtacağız (ağlamaklı bir ses tonu kullanıyor). ... Önce Allah rızası için, sonra ölmüşlerimizin hayrını, sonra kendi hayrımıza, kazadan beladan korunmamıza ama en önemlisi sevgili Peygamberimizin ruhuna hediye niyetiyle dağıtacağız bu Yasinler. Hepimiz arıyoruz. Evet kardeşlerim haydi arayın 0212 ... Sizler bu Yasini alarak, efendimizin ruhuna hediye edin. Vallahi büyük fazilettir. Özellikle bu Miraç gecesi. Arayın canlar. ... Alın efendimiz adına hediye edin. Aramaya devam edin. Son üç dakika bakın. Arayın Allah rızası için. Katılın kardeşlerim. Siz bu geceye önem, siz şu Yasinlere değer, efendimizin adına hediye niyetiyle alıyorsunuz ya bu size yeter. Arayın 0212... Sevgili Peygamberimizin adına dağıtmak için arayın. 39 liraya kardeşlerim. ... Çağrı merkezi numaralarımızı program boyunca aramaya devam edin. ... Bu gece Allah onu teselli ediyor. Biz Yasin kampanyamıza katılmayacak mıyız? Evet kardeşlerim arayın. ... İnanın hayırlar bire bin yazılıyor bu gece. (Yasin cüzü reklamı, 02.04.2019).

\subsubsection{Bayram FM Dinleyicilerinin Şanına Layık...}

Sunucular tarafından "Bayram FM dinleyicilerine yakışan bir arama olsun" denilerek dinleyenler teşvik edilmekte ve böylece Bayram FM'li olmanın gerekleri ve Bayram FM'liye yakışanların ne olduğu sunulmaktadır. Burada aidiyetler üzerinden bir satış söz konusudur:

Şöyle telefonları elimize alalım. Bayram FM dinleyicilerinin şanına layık bir şekilde aramalarınız gelsin, çağrılarınız gelsin dostlar. İşte numaramız 0212... (Kur'an reklam1, 29.03.2019).

Çözümlemesi yapılan reklamlarda en çok karşılaşılan kelimeler; "kardeşlerim" (48), “Allah" (30), “Kur'an" (23), “Yasin" (16), “dostlar" (10), "efendim" ve "peygamberimiz" (7), 
“inşallah" (5), "muhteşem" ve "mucize" (3) şeklindedir. Bu kelimeler reklamlarda dini kavramların kullanımının yoğunluğunu ortaya koymaktadır.

Program sunucuları, aynı zamanda, radyoda yayınlanan ilahileri söyleyen kişiler olarak düğün, nişan gibi organizasyonlarda da görev almakta ve dinleyicileri kendilerini davet etmeleri konusunda teşvik etmektedirler. $\mathrm{Bu}$ da reklamın bir başka boyutunu oluşturmaktadır. Reklamı yapılan diğer bir durum da umrelerdir. Program sunucuları eşliğinde yapılan umreler de söz konusudur. Umreler, tanışıklığı arttırıcı bir rol oynamaktadir.

\subsection{Yayına Bağlanan Dinleyiciler ile Sunucular Arasındaki Geçen Diyaloglar}

$\mathrm{Bu}$ başlık altında, program sunucuları ile dinleyiciler arasında gerçekleşen konuşmalara yer verilecektir. Dinleyici-sunucu diyalogları herhangi bir değerlendirme yapılmadan aktarılmaya çalışılacak ve analizler değerlendirme ve sonuç bölümünde yapilacaktır.

\subsubsection{Bilmediğimizi Bildik, Bilmediğimizi Öğrendik...}

Dinleyicilerin, sunuculara yönelik hitapları, aradaki ilişkinin niteliğini ortaya koyması açısından önemlidir. Takipçilerden on üç tanesi sunucuya "hocam" diyerek hitap etmiş, bir takipçi de "öğretmen" olarak nitelemiştir ve bunu bir sevinç ve övünç sebebi saymıştır:

Ne mutlu bizlere sizler gibi öğretmenimiz var. Biz ne kadar şanslı bir insanız ki sizlerle karşılaştık. Rabbime binlerce şükürler olsun. Bilmediğimizi bildik, bilmediğimizi öğrendik. Ben yıllardır bu radyoyu dinliyorum. Allah'ım bin kere razı olsun. Bin kere bir değil (D8).

Dinleyiciler, sunuculara kendilerini aydınlattıkları, bilmediklerini onlara öğrettikleri için teşekkür ederken, onları tanımadan önceki hayatlarının boşa gittiğini söylemektedir:

Allaha şükür sizleri dinliyoruz, takip ediyoruz, daha iyi oluyoruz. Evlerimize konuk oldunuz Allah razı olsun, böyle programları yapanlardan. Bilmediklerimizi biliyoruz, duymadıklarımızı, hatalarımızı öğrendik hocam. Biz şimdiye kadar boşa yaşamışız diyoruz hocam. Boşa yaşamışız hocam (D20). 


\subsubsection{Zekât Verir misin, Sadaka Verir misin?}

Program sunucuları ile dinleyicilerin, karşılıklı muhabbet ve soruları, aralarındaki iletişimin niteliğini açık etmesi bakımından önemlidir. Sunucuyla dinleyici arasında gerçekleşen aşağıdaki diyaloglar bu durumu örneklemektedir:

S1: Zekât verir misin, sadaka verir misin?

D1: Vermez olur muyum ya. Benim gönlüm bol.

S1: Maşallah, maşallah.

D1: Bir ekmeğim olursa on kişiyle paylaşırım hocam.

S1: Allah razı olsun. Belli zaten belli. Allah razı olsun. ${ }^{84}$

Sunucu (S1) ile D3 arasından geçen bir başka diyalog ise şu şekildedir:

S1: Kaç çocuk var.

D3: Üç tane oğlum var ellerinizden öper.

S1: Kaç yaşlarında?

D3: On, on altı, on sekiz.

S1: Şimdi bunları sabah namazına kaldırıyor musun?

D3: Hocam isimleri Hasan, Hüseyin, Mehmet. Diyorum ya ben zorluyorum mesela oruca da zorluyorum, namaza da zorluyorum. Onlar kendi kılmıyor. Yoksa ben zorluyorum sürekli.

S1: Sabah böyle kaldırıyor musun, kıyamıyor musun, doğru söyle bak.

D3: Yok sabah namazla beraber uyanıyorum zaten. Okula erken gittikleri için.

S1: Onları uyandırmıyorsun yani he?

D3: Uyandırıyorum da erkenden diyorum ya onlar uyku sersemi. Anca bir çay içip okula gidiyorlar. Yoruluyorlar.

S1: Ah ah. (Kürtçe bir söz söylüyor.) Hey günler hey.

D3: Şimdiki gençlik çok zor hocam. Şimdiki gençliği zapt etmek çok zor, çok zor.

\footnotetext{
${ }^{84}$ Dinleyiciler ile sunucular arasında geçen başka diyalog ise şu şekildedir: S3: Demek ki tekrar iş hayatına atıldınız. (Buradan tanıdığı ortaya çıkıyor). D15: Evet hocam.

S3: Ne güzel ne güzel. O zaman maaşı, aylığı paylaşıyoruz de mi inşallah?

D15: Canın sağ olsun. Paranın lafi mı olur hocam ya. Para elimizin kiri hocam ya.
} 
S1: Biz de genciz bak. Biz de genciz elhamdülillah. (Aynı sunucu başka bir dinleyiciye emekli edin bizi diyerek yaşlandığını ifade ediyor). Biz şimdi gidip de top mu oynuyoruz?

\subsubsection{Ben Her Ürününüzden Aldım...}

Reklamlarda kullanılan dilin, satışı yapılan ürünleri almanın büyük sevap kazandıracağı üzerine kurulu olmasının sonucunda, dinleyiciler tarafından, satılan ürünlerin alınması sanki dini bir gereklilikmiş gibi hissedilmektedir. Ürünlerin alındığı sunuculara özellikle belirtilmekte ve böylece sorumluluğu yerine getirmiş olmanın verdiği huzur hali aktarılmaktadır. D2 “abi ben Kur'an-1 Kerim siparişi verdim” derken, D17 ise "ben her ürününüzden aldım. Duanız için, dua etmenizi bekliyorum" şeklindeki ifadesiyle, sorumluluğun karşılığında ödül olarak dua beklemektedir.

\subsubsection{Hocam Bizlere de Dua Edin...}

Dinleyiciler, sunucuları özellikle dua talebi için aramakta ve sunuculardan kendileri ve sevdikleri için dua isteğinde bulunulmaktadırlar:

Hocam bizlere de dua edin, duanızı bekliyoruz inşallah, Rabbim kimseyi sıkıntıda koymasin (D3).

Ben dua istiyorum (D6, D7, D17, D24). ${ }^{85}$

D25 ise "arkadaşım birini seviyor ama hani biraz aileler karşı çıkıyor, kavuşmak istiyor bir türlü kavuşamıyor. Çok üzülüyor" diyerek arkadaşının sevgilisine kavuşması için dua istemektedir.

\subsubsection{Senin Gibi Hayırlı Bir Evlat Yetiştirmiş Hocam...}

Dinleyiciler sunuculara büyük bir saygı göstermekte ve onların varlığını şükür nedeni olarak görmektedirler. Aşağıda yer alan konuşmalar bu durumu ortaya koymaktadır:

D12: Allah annenden bir değil bin razı olsun. Senin gibi hayırlı bir evlat yetiştirmiş hocam.

S1: Estağfurullah estağfurullah. Ben hoca değilim.

D12: Ne mutlu bizlere sizler gibi öğretmenimiz var.

\footnotetext{
${ }^{85}$ D6 ne için ve kimler için dua istediğini ise şu şekilde açıklamaktadır; "Gelinimiz rahatsız, kız kardeşim rahatsız bir de babam rahatsız onun ruhuna. Hepsi bir anda olsun. Zaten düşüremiyorum. Hep arıyorum.”
} 
S1: Estağfurullah, estağfurullah.

Programlar ve sunucular, dinleyiciler tarafından övülmekte hatta kendilerine ilaç gibi geldiği söylenmektedir:

D2: Abi programin çok güzel.

S1: Daha dur başlamadık. Daha dur programa yeni başladık.

D2: Evet. Vallahi çok güzel bilmiyorum ya. İlaç gibi.

S1: Estağfurullah, estağfurullah.

D16 sunucuya "biz sesinizi duyuyoruz çok iyi oluyoruz, çok güzel hocam" derken, D19 “bütün gün sizi dinliyorum”, D24 "Allah sizi başımızdan eksik etmesin. Huzur Bayram FM'de", 86 D25 ise "ağzınıza yüreğinize sağlık, çok güzel dualar ediyorsunuz, çok güzel şeyler okuyorsunuz" gibi ifadelerde bulunmaktadır.

\subsubsection{Ekibi de Alır Gelirim Oraya...}

Radyoda yer alan ilahilerin birçoğunun radyo sunucuları tarafından söylenen ilahilerden oluştuğu yukarıda değinilmişti. Bu durumla alakalı olarak bir sunucu, dinleyicisine (D4) çocuklarının dügününe, ilahi korosunu ve kendisini çağırmasını söylemektedir. Diyalog şu şekildedir:

S2: İnşallah onların da dügününü güzel ilahili yaparsın yüce Rabbimin izniyle.

D4: Valla diğerlerini ilahi istedik de karşı taraf istemedi.

S2: İnşallah yine iste, yine olur inşallah.

D4: İnşallah bu kız, ${ }^{87}$ biraz yakın, o istiyor da.

S2: E tamam. Unutma ha bu kardeşini. Bak dinle dinle. İrfan abi gelirim. Ararsın dügünü var kızımın dersin. Ekibi de alır gelirim oraya.

Sunucuyu (S2) torununun düğününe çağıran D22 ile sunucu arasında geçen bir görüşme söz konusudur. Görüşmenin sonunda sunucu, aşağıdaki ifadeleri kullanmakta ve dinleyicilere kendisini çağırmalarına yönelik mesaj vermektedir:

\footnotetext{
${ }^{86} \mathrm{Bu}$ ifade daha çok "huzur İslam'da" şeklinde kullanılırken burada huzurun Bayram FM'de olduğu ifade edilmektedir.

${ }^{87}$ Konuşma evin en küçük kızı üzerinden yapılıyor. “Bu kız”dan kasıt evin en küçük kızıdır. Liseye gitmektedir.
} 
Selma anne bu evladını seviyor bak. Torununun düğününe beni çağırdı. Adam sevdiğini çağırır tabi. Yani. Allah razı olsun. Bizde inşallah onları utandırmayacağız. Bu sevgiye layık olacağız. Yoksa ben Ahmet'i seviyorum ama Mehmet'i çağırırsam ne anlamı kaldı Ahmet'e olan sevgimin. Yani. O kadar. İnsan sevdiğini tutar. İnsan sevdiği ile beraber yola çıkar. İnsan sevdiğini destekler kardeşim.

\subsubsection{Benim Sıkıntılarım Var...}

Dinleyiciler dert ve sıkıntılarını dile getirmek ve bu konuda zihinsel bir rahatlama yaşamak için de radyoyu aramaktadır. D13'ün “benim sıkıntılarım var da ondan aradım”"88 (ağlıyor) şeklindeki ifadesi bunlardan birisidir.

\subsubsection{Bir Al Kullan da Ondan Sonra Bak Gör...}

Reklamı yapılan ürünler, dinleyicilerle yapılan konuşmalar esnasında hatırlatılmakta ve takipçiler, almaya teşvik edilmektedir. D16 ile program sunucusu arasında geçen bir konuşma şu şekildedir:

D16: Ben çalışıyorum hocam. Bu akşam mesaiye kaldım. Fabrikadayım.

S1: Eve gidince ayağın ağriyor, belin ağriyor, kolun ağriyor değil mi?

D16: Evet, ne yapacağız hayat. Mecbur çalışacağız. Çalışmasak da olmuyor.

S1: Nasıl ne yapacağım. Termal krem alacaksın. (Öncesinde reklamı yapıldı) Allah Allah. Tabi canım. İnan bana teşekkür edeceksin. Bir al kullan da ondan sonra bak gör. Abim ne kadar doğru söylüyor diyeceksin. Termal krem öyle böyle bir krem değil. ${ }^{89}$

\subsubsection{Ben de Artık Yavaş Yavaş Yorulmaya Başladım...}

Dinleyiciler tarafından radyoyu aramak ve bağlantı kurmak, sunucular ile görüşmek şükür gerektirecek bir davranış olarak kabul edilmektedir. Bu sebeple, radyoyu arayan dinleyicilerin birçoğu devamlı arayıcıdır. D3 “Allah'ıma çok şükürler olsun, sonunda bağlanabildim. Çok şükür" demektedir. D23 gibi bazı dinleyiciler günde iki defa bile aramaktadır. D23 şunları söylemektedir: "Hocam ben aramadan duramıyorum. Öğlende

\footnotetext{
${ }^{88}$ Diyaloğun devamı şu şekildedir:

S4: Belli zaten. Dua edelim. Tüm dinleyicilerden dua isteyelim olur mu?

D13: Tamam. (Konuşma sona eriyor).

${ }^{89}$ Aynı dinleyici konuşmanın başka bir bölümünde aramak için kontörünün olmadığını o sebeple arkadaşlarının telefonundan aradığını söylüyor. "Hocam arkadaşlarım ... hocayı bir ara konuş dedi. Ya arkadaşlar benim kontörüm yok dedim. Ya istediğin kontör olsun dediler telefonunu verdiler. Dediler bir ara konuş.”
} 
aradım konuştum." Bununla birlikte devamlı arayan dinleyiciler, sunucular tarafından hoş karşılanmamaktadır. Sunucu, "ama şöyle düşüremeyenlere bir şey yapalım yani. Yani her gün böyle aynı şeylerden ben de artık yavaş yavaş yorulmaya başladım. Böyle biraz bir şey yapalım yani ara ara" 90 diyerek tepkisini göstermektedir.

\subsubsection{Damarlarımdaki Kan Gibi, Aramadan Duramıyorum...}

Dinleyicilerden bazıları radyoyu sohbet etme ve sosyalleşme aracı olarak da kullanmakta ve Bayram FM'in onlar için ne anlama geldiğini "damarımızdaki kan gibi" benzetmesiyle anlatmaktadırlar. Bu konuda D23 şunları söylemektedir:

Bayram FM derler ya kanımıza işlemiş, damarlarımdaki kan gibi, aramadan duramiyorum ... Bir arayayım sohbet edeyim dedim. Canlı canlı sohbet edeyim dedim...Ya bilmiyorum bende çok büyük bir yer var, yeriniz acayip farklı. Bayram FM'i hafta sonu bile dinlemeye çalışıyorum.

Aynı dinleyici, radyoyu bir aile olarak görmekte ve Bayram FM ailesi olduklarını söylemektedir:

Biz bir aile olmuşuz ki birbirimize selamlar gönderiyoruz. Sizler vesile olduğunuz, sizin muhabbetiniz bizi bağlıyor. ${ }^{91}$

Sunucular ve dinleyiciler üzerinden elde edilen verilerden hareketle ulaşılan sonuçlar, değerlendirme ve sonuç bölümünde incelenecektir.

\section{DEĞERLENDİRME VE SONUÇ YERINNE}

Popüler kültür doğrultusunda gerçekleşen ilişkilerde genellikle taraflardan biri baskındır ve bu eşit etki gücüne sahip olunmayan bir duruma neden olur. Ortaya çıkan eşitsizliğin meşrulaştırılmasına yönelik bu noktada, Gramsci'nin hegemonya olarak isimlendirdiği kavram devreye girmektedir. Hegemonyada salt kaba kuvvete dayalı bir hakimiyet değil; fiziksel gücün yanında hegemonyaya karşı rızanın alınmasıyla gücün

\footnotetext{
${ }^{90}$ Sunucu konuşmanın başında "bana kırılmayın, darılmayın ama şu düşüremeyenlere bugün bir yer verelim" diyerek sürekli arayanların düşüremeyenlere de müsaade etmelerini istemektedir.

${ }^{91}$ Radyoyu sıklıkla arayan dinleyiciler hiç yüz yüze gelmemelerine rağmen birbirlerine selam göndermektedir. Sürekli bir arama olduğu için dinleyicilerde birbirlerinin kim oldukları, nereden aradıkları ve ne iş yaptıklarını bilmekte ve aradıklarında onlara selam göndermektedir. D23 bu durumu aile olmak üzerinden yorumlamaktadır.
} 
meşrulaştırılması ve maruz kalanlarca içselleştirilmesi de söz konusudur. Rızanın kazanılmasıyla birlikte var olan eşitsiz ilişki madunlar tarafından sorun olmaktan çıkar ve her şeyin olması gerektiği gibi olduğu, başka türlüsünün mümkün olamayacağı düşüncesi hâkim olur. Çalışmanın konusunu oluşturan Bayram FM'de de buna benzer bir süreç işlemektedir. Bir ilişki söz konusudur ve ilişkide pazarlığa dayalı bir alışverişlerle birlikte, taraflardan biri (radyo tarafı) diğerine (dinleyiciler) karşı oldukça baskın bir rol oynamaktadır.

Reklam ve sunucu-dinleyici diyaloglarının analizi sürecinde birçok sonuca ulaşılmıştır. “Genel olarak kitle iletişim araçlarının kullanılma alışkanlığı ve bu araçların sunduğu yararlara ilişkin inançlar ve beklentiler, kişilerin toplumsal koşulları ve psikolojik ön-eğilimleri tarafından belirlenir. Bu inanç ve beklentiler, araçların seçimine ve kullanımına ilişkin özgül davranışları biçimlendirir." $92 \mathrm{Bu}$ duruma uygun olarak Bayram FM, düşük gelirli bir işte çalışmak, para kazanmak için başka bir şehre göç etmek, kişisel ya da toplumsal birtakım yoksunluklar içerisinde bulunmak, yalnızlık ve yaşlılık gibi belli ortak özelliklere sahip insanlar tarafından daha fazla takip edilmektedir. Radyonun benzer profillere sahip insanlarca dinleniyor olması, içerisinde bulunulan sosyo-ekonomik şartlarla kanalın dinlenmesi arasında bir bağlantının olduğunu göstermektedir. Sahip olunan sosyoekonomik durumun getirdiği birtakım kısıtlamalar radyo sayesinde aşılmakta, bu ise bir bedel karşılığında yapılmaktadır.

Çoğunlukla benzer kimliklere sahip dinleyiciler, Bayram FM'de kendilerinden bir şeyler bulmakta ve bu nedenle başka herhangi bir radyo istasyonu yerine Bayram FM'i takip etmektedirler. Sokak jargonuyla konuşan, ${ }^{93}$ amatör yayınlar yapan ve halk İslam'1 ya da folk din olarak kabul edilen bir din dili kullanan ${ }^{94}$ sunucular, bütün olarak dinleyici kitlesiyle ortak paydayı oluşturmaktadır. Dinleyicilerin inandığı, benimsediği ve değer verdiği birtakım öğeleri önemseyen radyo, onlar açısından bir cazibeye bürünmekte ve söz konusu etkenler ekonomik kazanç için araçsallaştırılmaktadır. Kanalın belli bir kesim tarafından dinlenmesinin altında yatan bir başka neden ise dinleyicilerin kolaylıkla radyoyla iletişim kurabilmeleri ve sunucular tarafından muhatap alınmalarıdır. Burada dikkat edilmesi gereken nokta, sadece radyoya kolay erişim değil, konuşmaların dinleyiciler açısından

\footnotetext{
${ }^{92}$ Mutlu, Globalleşme Popüler Kültür ve Medya, 99.

${ }^{93}$ Hele, yav, aney gibi daha çok halk arasında kullanılan kelimeler sunucular özellikle de arayanlar tarafindan çok sevildiği söylenen bir sunucu tarafından bolca kullanılmaktadır. Gündelik hayatta sıkça karşılaşılan "iş güç nasıl", "çoluk çocuk nasıll", "nerelisin", "ne iş yapıyorsun” gibi sorular sunucular tarafindan dinleyicilere sorulmakta aynı zamanda konuşmalar esnasında, "gel yumurta yiyelim gel", "maaşın yarısı benim" gibi gündelik hayatta karşılaşılan ifadeler kullanılmaktadır. Bu dil radyoyu dinleyenlerle ortaklığı oluşturan önemli bir özelliktir.

${ }^{94}$ Yasin cüzlerini dağıtmanın büyük sevap getireceği yönündeki inanç hem halk dininin hem de popüler kültürün örneklerinden birisidir ve bu radyoyla ortak paydayı oluşturmaktadır.
} 
anlaşılabilir bir içeriğe ve forma sahip olmasıdır. Radyoya kolay erişim, belli noktalarda sınırlı imkanlara ${ }^{95}$ sahip dinleyicilere varlık kazandırarak, bu grup içerisinde yer alan insanlar için kendi küçük dünyalarından daha büyük dünyalara açılan bir pencere işlevi görmektedir. Söz konusu var olmanın, görüntü yerine ses üzerinden gerçekleştirilmesi ise dinleyiciler açısından önemli bir motivasyon sağlayıcıdır. Öyle ki genel olarak sesle varlık kazanma, görüntüyle var olmaktan daha kolaydır ve burada görünmeden var olmanın cazibesi söz konusudur. Takipçilerin ürün almalarının arkasında yatan önemli motivasyon araçlarından biri de var oldukları kanalın sürekliliğini sağlamaya yöneliktir. Radyo varlığını sürdürdükçe dinleyicilerin kendilerini sesle ifade ettikleri, gerçekleştirdikleri alanın varlığ da sürmüş olacaktır. "Allah sizi başımızdan eksik etmesin. Huzur Bayram FM'de" (D24) gibi ifadeler bu durumu desteklemektedir.

Radyonun dinlenme nedenlerinden birisi de 'oyalanma' ve 'kaçış'tır. ${ }^{96}$ Gündelik hayatın sıradanlığı ve sıkıcılığının dayattı̆̆ı sınırlamalardan kaçış, zihinsel ve duygusal rahatlama gibi sebepler radyonun dinlenme gerekçeleri arasında yer almaktadır. Bu, bir tür rehabilitasyondur. Dinleyicilerin dertlerini, sıkıntılarını sunuculara aktarması ve onlardan dua istemeleri de bununla bağlantılıdır. Bu noktada Bayram FM sakinleştirici, yatıştırıcı ve uyuşturucu bir rol oynamaktadır. Dinleyicilerin radyonun kendilerine "ilaç gibi" geldiğini söylemeleri bu durumu açık etmektedir. Radyonun takip edilmesinin altında yatan bir diğer neden ise kurulan kişisel ilişkilerdir. Dinleyiciler radyo sayesinde hem sunucularla hem de diğer takipçilerle iletişim kurmakta, böylece yalnızlık duygularını da gidermektedirler. “Allah'a şükür sizleri dinliyoruz, takip ediyoruz, daha iyi oluyoruz. Evlerimize konuk oldunuz" (D20) "aramadan duramıorum, arayayım sohbet edeyim dedim" (D23), "biz bir aileyiz" (D23) gibi ifadeler bu durumu desteklemektedir. Dinleyiciler açısından önemli olan bu işlevsel yönler, radyo yöneticileri ve sunucuları tarafından bilinmekte ve daha fazla kar sağlamaya yönelik araçsallaştırılmaktadır.

Radyonun aranması, bazı dinleyiciler açısından bağımlılığa dönüşmüş ve bir ihtiyaç halini almıştır. Radyoyu öğle vakti de aradığını ve aramadan duramadığını söyleyen D23'ün "hocam ben aramadan duramıorum. Öğlende aradım konuştum ama öyle bir şey ki Bayram FM, derler ya kanımıza işlemiş, damarlarımdaki kan gibi, aramadan duramıyorum" ifadeleri bu durumu ortaya koymaktadır. Aynı şekilde sunucunun sürekli arayan dinleyicilerden arayamayanlara da fırsat vermelerini istemeleri ve D16'nın "sesinizi duyuyoruz, çok iyi oluyoruz" şeklindeki sözleri de bu sonucu desteklemektedir. Söz konusu

\footnotetext{
${ }^{95}$ Sınırlı imkanların neler olduğu dinleyici profillerinden belirtilmiştir. Düşük gelirli maaş, başka bir şehre göç zorunluluğu, yaşlılık ve yalnızlık bunlardan bazılarıdır.

${ }^{96}$ Kaçış daha çok kullanımlar ve doyumlar yaklaşımı içerisinde kullanılmaktadır. Daha detaylı açıklamalar için bk. Mutlu, Globalleşme Popüler Kültür ve Medya.
} 
durum yukarıda ifade edilen kendini gerçekleştirme imkânı, yalnızlık ve sahip olunan sosyo-ekonomik şartlarla bağlantılıdır.

Reklamlarda satışı yapılan nesneler, alıcılar (dinleyiciler) tarafından "kutsal" çerçevesinde değerlendirilen ürünlerdir. Satışlarda kutsal vurgusunun öne çıkartılması bu durumla bağlantılıdır ve reklamlarda bir nevi 'kutsalın satışı' yapılmaktadır. Kur'an bunların en başında yer alırken, 'Yasin cüzleri, seccadeler, hurma ve mevlit hediyeleri' de pazarlanan diğer kutsalları oluşturmaktadır. İlk bakışta doğrudan kutsal ile bağlantısı kurulamayan ürünler de kutsal bir anlam yüklenerek dinleyiciye sunulmaktadır. "Gül kokulu, Peygamber kokulu on adet tespih" ifadesinden de anlaşıldığı gibi gül sadece kokan bir gül olarak değil, Peygamberin kokusu olarak sunulmakta ve 'Peygamber kokulu tespih' alınan ürünlerin yanında hediye edilmektedir. Reklamlarda sadece kutsal ve kutsallaştırılmış nesneler değil benzer şekilde 'kutsal olan gün ve geceler' de ürünlerin daha fazla satışı için kullanılmaktadır. 'Cuma, üç aylar ve kandil geceleri' bunlardan bazılarıdır. Özellikle bu tür gün ve gecelerde yapılan reklamlarda, söz konusu kutsal zaman vurgusu oldukça yoğun bir şekilde hissedilmektedir. “Bugün (Cuma) yapılan iyilikler bol sevap kazandıracak", "şu kandilin bereketiyle arayalım" gibi örnekler bu sonucu desteklemektedir. Reklamlarda yer alan bir diğer kutsal ise Peygamberin kendisidir. Peygamber daha fazla ürün satışı için araçsallaştırılmakta ve dinleyicileri ikna etmenin bir başka yöntemi olarak rol oynamaktadır. “Sizler bu Yasin'i alarak efendimizin ruhuna hediye edin. Vallahi büyük fazilettir" ifadelerinde de açık bir şekilde görüldüğü gibi insanların peygambere yönelik duyguları kullanılmakta ve daha fazla ürün satışı hedeflenmektedir. Böylece kültür endüstrisi, kutsal nesneleri ve Yasin cüzü gibi popüler dini öğeleri metaya dönüştürmekte ve pazarlamaktadır. Bu noktada kutsallıklar, dinleyiciler üzerinde maddi kazanca yönelik hegemonyanın kurulmasında araç görevi görmekte ve dinleyicilerin dini duyguları istismar edilmektedir.

Reklamlarda satışı yapılan ürünleri almak ibadet gibi sunulmakta ve karşılığında bol sevap kazandıracağı vurgulanmaktadır. Yukarıda ifade edilen kutsallıklar gibi sevap öğesi de takipçilere daha fazla ürün satmak için araçsallaştırılmakta ve dinleyiciler yönlendirilmektedir. 'Allah'ın rızası, peygamberin şefaati' de bu bağlamda önemli bir motivasyon aracı olarak kullanılmaktadır. “Torbalarımızı dolduralım dostlar. Torbalarımızı dolduralım. Sevap hanelerimiz dolsun dostlar" ve "Yasinleri dağıtalım, Peygamber efendimizin şefaatine nail olalım ... siz şu Yasinleri efendimizin adına hediye niyetiyle alıyorsunuz ya bu size yeter" gibi ifadeler bu durumu ortaya koymaktadir.

Sevap gibi dua faktörü de araçsallaştırılmaktadır. Bayram FM'de dualarla örülü bir dil hem sunucular hem de dinleyiciler tarafından oldukça fazla kullanılmaktadır. 
Takipçilerin arama nedenlerinden biri sunuculardan, kendilerine ve sevdiklerine yönelik dua talebidir. Dinleyiciler tarafından kutsanan ${ }^{97}$ sunucular, ürün alan kişilere dua etmekte böylece dua dinleyicilerden daha fazla para elde edilmesine yönelik bir araç olarak kullanılmaktadır. 98 "Bizlere de dua edin hocam" isteği sıkça tekrarlanmakta ve sunucular yoğun bir şekilde dua etmektedirler. Sunucuların kutsanmasının sonucu olarak dua faktörü, hegemonyaya rızayı oluşturan önemli bir etkendir. Karşıdaki insanın kutsanması, onun dediklerinin yapılması sonucunu beraberinde getirmektedir ve bu daha fazla ürün satışında rol oynamaktadır.

Bayram FM'li olmak için Bayram FM dinlemek yetmez. Dinleyicilerin, aynı zamanda Bayram FM'li olmanın bazı gereklerini de yerine getirmesi gerekir. Bunlardan birisi satılan ürünlerin alınmasıdır. Reklamlarda, Bayram FM dinleyicilerine yakışacak bir aramanın/ürün alımının olması istenmekte, böylece Bayram FM aidiyeti daha fazla maddi kazanç elde etme amacıyla kullanılmakta ve Bayram FM'li olmaya yönelik bir kimlik bileşeni sunulmaktadır. Kimliğin sınırlarının belirlenmesi egemen tarafı göstermekte ve sunulan bu kimlik özelliği dinleyiciler tarafından alımlanmaktadır. Radyoyu arayan dinleyiciler ürünleri aldıklarını özellikle belirtmekte ve sunuculara Bayram FM'li olmanın gereğini yerine getirdikleri mesajinı vermektedirler.

Dinleyiciler radyo sayesinde dini konularda bilgi sahibi oldukların ifade etmektedirler. D8' in “Ne mutlu bizlere sizler gibi öğretmenimiz var. Biz ne kadar şanslı bir insanız ki sizlerle karşılaştık. Rabbime binlerce şükürler olsun. Bilmediğimizi bildik, bilmediğimizi öğrendik" ifadesi ve D20'nin "bilmediklerimizi biliyoruz, duymadıklarımızı, hatalarımızı öğrendik hocam. Biz şimdiye kadar boşa yaşamışız diyoruz hocam. Boşa yaşamışız hocam" şeklindeki sözleri bu durumu ortaya koymaktadır. Radyonun bilgi kaynağı olarak rol oynaması dinleyiciler üzerinde iktidarını güçlendiren önemli bir faktördür.

\footnotetext{
${ }^{97}$ Böyle bir ifadenin kullanılma sebebi, dinleyicilerin sunuculara yönelik kullandıkları hitap cümleleri ve daha da önemlisi onlardan 1srarla kendilerine dua etmelerini istemeleridir. Bu kadar yoğun bir dua talebi, duası kabul olacağ düşünülen kişilerden talep edilmektedir ki bu bir yönüyle o kişinin Allah katında duası kabul olan kutsal bir insan olduğunun kabulüdür. Bu davranış daha çok dini grup ve cemaatlerde karşılaşılan bir özellik olmakla birlikte Bayram FM örneğinde de gözlenmiştir.

${ }^{98}$ Dua meselesi önemli bir konudur. "İnsanların duaya yönelme nedenleri ve sıklıkları", toplumsal olarak araştırılmaya değerdir. "İnsanların dualarında artış ve gerileyişler ne zaman olmakta, insanlar dualarında neleri talep etmekte ve kimlerden istemektedir" gibi sorular önemli bir araştırma konusunu oluşturmaktadır. Bayram FM örneği üzerinden konuşulursa, "dinleyicilerin içerisinde bulunduğu sınırlı belki de kötü durumla dua talebinin bu kadar fazla bir şekilde dile getirilmesi arasında ne gibi bir bağlantı vardır" sorusu sorulabilir. Bunun daha detaylı araştırılması gerekir.
} 
Dini radyolara yönelik yapılan diğer çalışmalarla karşılaştırıldığında, dinleyicilerinin ve sunucu-dinleyici konuşmalarının çoğunluğunu kadınların oluşturduğ ${ }^{99}$ Bayram FM'de herhangi bir kadın sunucunun olmaması Azak'ın çalışmasında ifade edilen durumu doğrulamaktadır. ${ }^{100}$ Aynı zamanda, Akgül'ün araştırmasında ortaya çıkan dinleyici profillerinin bir benzeri ${ }^{101}$ burada da görünürlük kazanmıştır. ${ }^{102}$ Diğer taraftan Akra FM'in daha çok bilişsel ihtiyaçlara karşılık gelmekle birlikte duygusal, kişisel, sosyal ve rahatlama ihtiyaçlarını da karşıladığını ${ }^{103}$ söyleyen Yetgindă̆’’n elde ettiği sonuç, Bayram FM dinleyicilerinde de gözlenmiştir. Bayram FM, takipçileri açısından rahatlama, kaçış gibi birtakım işlevlere sahiptir.

Geleneksel kurumlar artık işlevlerini yerine getirme konusunda zorlanmaktadır. Aidiyet ihtiyacının geleneksel olarak karşılandığ yalnızlık ve terk edilmişlik duygusunu ortadan kaldıramadıklarında kullanışlı oldukları söylenemez. Bu durumu ortaya çıartan göç ve şehirleşme gibi belli birtakım nedenler vardır. Bayram FM dinleyicilerinde de buna benzer bir durum söz konusudur. Ortaya çıkan aidiyet boşluğu Bayram FM tarafından doldurulmaya çalışılmaktadır. Radyoyu daha çok ailenin yerine koyanların, Bayram FM'i dini bilgi kaynağı olarak görenlerin ve iş bulma amacı olmak üzere çeşitli nedenlerle doğup büyüdükleri yerlerden farklı kentlere göç eden kimselerin radyoyu aramaları söz konusu durumu desteklemektedir.

Sonuç olarak, reklamlar ve sunucu-dinleyici konuşmaları üzerinden yapılan bu çıarsamalar meseleye popüler kültürden çok kültür endüstrisi boyutuyla yaklaşılması gerektiğini ortaya koymuştur. Kültür endüstrisi, kültürel ögelerin kâr amacıyla birer meta haline dönüştürülmesine ve kitlelerin söz konusu ürünler karşısında pasif konumuna gönderme yapmaktadır. Bayram FM'de hegemonya karşı rızayı oluşturan iki temel vardır; birincisi yaygın din eğitim olarak isimlendirilebilecek dini eğitim süreci diğeri ise dinleyicilere sunulan sosyalleşme imkanıdır. Sosyo-ekonomik nedenler ise söz konusu olan bu temelleri beslemektedir. Bayram FM dini öğeleri kâr amacıyla metaya dönüştürmekte ve dinleyicileri pasifleştirerek onlar üzerinde bir hegemonya kurmaktadır. Dinin hegemonya sağlayıcı bir güç olarak kullanılmasında 'kutsal nesneler, kutsal zamanlar, peygamber, sevap, dua ve popüler dini objeler' gibi öğeler etkili bir araca dönüştürülmekte ve daha fazla maddi kazanca yönelik olarak bir grubun (radyo tarafı) diğer grup (dinleyiciler) üzerinde

\footnotetext{
${ }^{99}$ Bayram FM'e ait sosyal medya hesapları ve radyoyu arayanlardan yola çıkılarak çoğunluğunun kadınlar olduğu sonucuna ulaşılmıştır.

100 Azak, "İslami Radyolar ve Türbanlı Spikerler", 93-108.

${ }^{101}$ Akgül'ün çalışmasında ortaya çıkan profiller için yirmi altıncı dipnota bakınız.

102 Akgül, "Medya ve Din: Radyo İletişimi ve Gözyaşı FM Örneği”, 39-86.

103 Yetgindağ, Dini Radyo Yayınlarının Alımlanmast: Akra FM Örneği, 113.

${ }^{104}$ Zygmunt Bauman, Kimlik, çev. Mesut Hazır (Ankara: Heretik Yayınları, 2019), 43.
} 
egemenlik kurmasını ve hegemonyaya maruz kalanların söz konusu hegemonyayı meşrulaştırmasını (rıza) sağlamaktadır. Aynı zamanda, dinleyiciler tarafından küçük kamularının dışına çıkma gibi maddi çıkarlar ve sevap kazanmanın verdiği haz, ahiret mutluluğunun kazanılmasına yönelik bir adım daha atmanın yaşattığı mutluluk hissi gibi soyut çıkarlar da radyo tarafının (yönetici ve sunucular) kurduğu hakimiyete karşı rızayı besleyecek şekilde kullanılmaktadır.

\section{KAYNAKÇA}

Adorno, Theodor. Minima Moralia. çev. Orhan Koçak \& Ahmet Doğukan. İstanbul: Metis Yayınları, 2000.

Adorno, Theodor. "Kültür Endüstrisini Yeniden Düşünürken". çev. Bülent Doğan. Cogito 36 (Yaz 2003), 76-77.

Akgül, Mehmet. “Medya ve Din: Radyo İletişimi ve Gözyaşı Fm Örneği”. Türk-İslam Medeniyeti Akademik Araştırmalar Dergisi 6/1 (Temmuz 2008), 39-86.

Akşam Gazetesi. “Din Sömürüsüne RTÜK Cezası”. Erişim 14 Nisan 2019. https://www.aksam.com.tr/guncel/din-somurusune-rtuk-cezasi/haber-300393

Akyön, Sinem. Türkiye'de Dini Yayıncılı̆̆ın Gelişimi: Dini Radyolar. Ankara: Ankara Üniversitesi, Sosyal Bilimler Enstitüsü, Yüksek Lisans Tezi, 2016.

Alemdar, Korkmaz \& Erdoğan, İrfan, Popüler Kültür ve İletişim. Ankara: Ümit Yayıncilık, 2005.

Altunbaş, Hüseyin. Başlangıçtan Günümüze Radyo ve Radyo Reklamcılı̆̆ı, Türkiye Yerel Radyo İstasyonlarının Reklam Aracı Olarak Kullanılışı, Sorunları ve Model Önerisi. Eskişehir: Anadolu Üniversitesi, Sosyal Bilimler Enstitüsü, Doktora Tezi, 2003.

Anderson, Benedict. Hayali Cemaatler. çev. İskender Savaşır. İstanbul: Metis Yayınları, 2017.

Azak, Umut. “İslami Radyolar ve Türbanlı Spikerler”. İslam’ın Yeni Kamusal Yüzleri. ed. Nilüfer Göle. 93-108. İstanbul: Metis Yayınları, 2013.

Aziz, Aysel. Radyo Yayıncılı̆̆ı. İstanbul: Nobel Yayınları, 5. Basım, 2018.

Bölükbaş, Kenan. Türkiye'de İnanç Gruplarının Kültürel Varoluşunda Topluluk Radyolarının Rolü. İstanbul: Marmara Üniversitesi, Sosyal Bilimler Enstitüsü, Doktora Tezi, 2016. 
Brecht, Bertolt. Radyo Kuramı ve Sinema Üzerine. çev. Süheyla Kaya. İstanbul: Agora Kitaplığı, 2012.

Davis Forgacs (haz.). Gramsci Kitabı. çev. İbrahim Yıldız. Ankara: Dipnot Yayınları, 2018.

Güney, Hamdi. Radyo Yayıncılı̆̆̆ıın Dijitalleşmesi ve Radyo Dinleyicisinin Dönüşümü. İstanbul: Marmara Üniversitesi, Sosyal Bilimler Enstitüsü, Doktora Tezi, 2007.

Horkheimer, Max \& Adorno, Theodor. Aydınlanmanın Diyalektiği. çev. Oguz Özügül. İstanbul: Kabalcı Yayınevi, 1995.

Kuruoğlu, Huriye. Propaganda ve Özgürlük Aracı Olarak Radyo. İstanbul: Nobel Yayınları, 2006.

Mutlu, Erol. Globalleşme Popüler Kültür ve Medya. Ankara: Ütopya Yayınları, 2005.

Neuman, Lawrence. Toplumsal Araştırma Yöntemleri. çev. Sedef Özge. Ankara: Yayınodası Yayınları, 2014.

Okutan, Birsen Banu. Türkiye'de Popüler Kültür Din ve Kadın. İstanbul: Düşün Yayınları, 2013.

Okutan, Birsen Banu. "Diyalektik Düşüncenin Negatif Seyri Theodor W. Adorno", Doğu'dan Batı'ya Düşüncenin Seyri. ed. Bayram A. Çetinkaya. 4/789-816. İstanbul: İnsan Yayınları, 2015.

Öztürk, Bahar. Radyo Yayıncılı̆̆ının Dijitalleşmesi ve Radyo Dinleyicisinin Dönüşümü. İstanbul: Marmara Üniversitesi, Sosyal Bilimler Enstitüsü, Doktora Tezi, 2017.

Pekdemir, Köksal. Din ve Zihniyet: Gençlik Üzerine Bir Araştırma. İstanbul: İstanbul Üniversitesi, Sosyal Bilimler Enstitüsü, Yüksek Lisans Tezi, 2018.

Radyo Televizyon Üst Kurulu, (RTÜK), “Üst Kurul Kararları”. Erişim 14 Nisan 2019. https://www.rtuk.gov.tr/ust-kurul-kararlari/6112-sayili-kanunun-10uncu-maddesinin-ikincifikrasinin-ihlali-nedeniyle-ipc-bayram-fm-pendik-produksiyon-ve-radyo-televizyonyayincilik-a-s/24095

Radyo Televizyon Üst Kurulu, (RTÜK), “Üst Kurul Kararları”. Erişim 14 Nisan 2019. https://www.rtuk.gov.tr/ust-kurul-kararlari/6112-sayili-kanunun-9uncu-maddesinin-altincifikrasinin-c-bendinin-ihlali-nedeniyle-idari-para-cezasi-bayram-fm-pendik-produksiyon-veradyo-televizyon-yayincilik-a-s/24152

Turner, Stephen. "Giriş: Sosyal Teori ve Sosyoloji”. çev. Nazan Gece. Sosyal Teori ve Sosyoloji. ed. Stephen Turner. 1-19. İstanbul: Küre Yayınları, 2013. 
Yaylagül, Levent. Kitle İletişim Kuramları, Egemen ve Eleştirel Yaklaşımlar. Ankara: Dipnot Yayınları, 2006.

Yetgindağ, Büşra. Dini Radyo Yayınlarının Alımlanması: Akra Fm Örneği. İstanbul: Arel Üniversitesi, Sosyal Bilimler Enstitüsü, Yüksek Lisans Tezi, 2015.

\section{EKLER 1:}

Dinleyicilerin Demografik Bilgileri

\begin{tabular}{|c|c|c|c|c|}
\hline Kişi & İsim & Meslek & Memleket & $\begin{array}{l}\text { Kayit } \\
\text { Tarihi }\end{array}$ \\
\hline 1 & Turan & $\begin{array}{c}\text { Kümes hayvancilığı } \\
\text { yapıyor }\end{array}$ & -105 & 25 Mart \\
\hline 2 & Fatma & $\begin{array}{c}\text { Ev hanımı olduğu } \\
\text { anlaşılıyor }\end{array}$ & - & 25 Mart \\
\hline 3 & Hatun & Ev hanımı & Maraşlı ama Kayseri'de oturuyor & 28 Mart \\
\hline 4 & İrfan & Bekçi & Vanlı ama Mersin'de yaşıyor & 28 Mart \\
\hline 5 & Nuray & Ev hanımı & Bursa & 2 Nisan \\
\hline 6 & Nurgül & Çalışıyor & İstanbul & 2 Nisan \\
\hline 7 & Ahmet & $\begin{array}{c}\text { Konuşmalardan esnaf } \\
\text { olduğu anlaşıllyor. }\end{array}$ & Adana & 2 Nisan \\
\hline 8 & Leyla & Yaşl1- çalışmıyor & Mersin'de yaşıyor ama Malatyalı & 4 Nisan \\
\hline 9 & İsmail & Belirtmiyor & Kayseri & 4 Nisan \\
\hline 10 & Ali & Esnaf (hazır giyim üzerine) & Mersin & 10 Nisan \\
\hline 11 & Mustafa & Öğrenci & Samsun & 10 Nisan \\
\hline 12 & Bahar & Yaşl1- çalışmıyor & - & 10 Nisan \\
\hline 13 & Şermin & - & - & 11 Nisan \\
\hline 14 & Hayriye & $\begin{array}{l}\text { Ev hanımı olduğu } \\
\text { anlaşılıyor }\end{array}$ & Balıkesir & 15 Nisan \\
\hline 15 & Meryem & Çalışıyor & İstanbul & 15 Nisan \\
\hline 16 & Mediha & Tekstilde çalışıyor & $\begin{array}{c}\text { Diyarbakırlı ama Mersin'de } \\
\text { yaşıyor }\end{array}$ & 15 Nisan \\
\hline
\end{tabular}

${ }^{105}$ Boş sütunlar dinleyicilerin konuşma esnasında konuya dair herhangi bir bilgi vermemesinden dolayıdır. 


\begin{tabular}{|c|c|c|c|c|}
\hline 17 & Emine & - & İzmir & 18 Nisan \\
\hline 18 & Hayri & - & Mersin & 18 Nisan \\
\hline 19 & Sefer & Servis Şoförü & Erzurum & 22 Nisan \\
\hline 20 & Hatice & Ev hanımı & Afyon (köy) & 22 Nisan \\
\hline 21 & Ayla & Çalışıyor & İzmir & 22Nisan \\
\hline 22 & Meliha & Çalışmıyor (yaşli) & Bursa & 23 Nisan \\
\hline 23 & Zeynep & Çalışıyor & İstanbul & 23 Nisan \\
\hline 24 & Hamza & Tekstil işiyle uğraşıyor & Mersin & 26 Nisan \\
\hline 25 & Gülcan & Halde çalışıyor & Mersin & 26 Nisan \\
\hline
\end{tabular}

EKLER 2:

Reklam türü ve reklam tarihleri

\begin{tabular}{|c|l|l|}
\hline Reklam & Reklam Türü & Reklam Tarihi \\
\hline Reklam 1 & Medine Hurması & 25 Mart \\
\hline Reklam 2 & Kur'an & 29 Mart \\
\hline Reklam 3 & Yasin Cüzü & 02 Nisan \\
\hline Reklam 4 & Kur'an Hatim Seti & 11 Nisan \\
\hline Reklam 5 & Krem & 18 Nisan \\
\hline Reklam 6 & Çörek Otu Yağ1 & 24 Nisan \\
\hline
\end{tabular}

